\title{
Post weaning diarrhea in pigs: risk factors and non-colistin-based control strategies
}

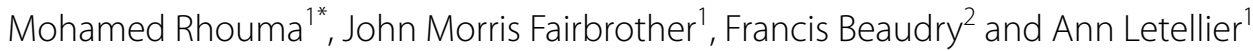

\begin{abstract}
Post-weaning diarrhea (PWD) is one of the most serious threats for the swine industry worldwide. It is commonly associated with the proliferation of enterotoxigenic Escherichia coli in the pig intestine. Colistin, a cationic antibiotic, is widely used in swine for the oral treatment of intestinal infections caused by E. coli, and particularly of PWD. However, despite the effectiveness of this antibiotic in the treatment of PWD, several studies have reported high rates of colistin resistant $E$. coli in swine. Furthermore, this antibiotic is considered of very high importance in humans, being used for the treatment of infections due to multidrug-resistant (MDR) Gram-negative bacteria (GNB). Moreover, the recent discovery of the mcr-1 gene encoding for colistin resistance in Enterobacteriaceae on a conjugative stable plasmid has raised great concern about the possible loss of colistin effectiveness for the treatment of MDR-GNB in humans. Consequently, it has been proposed that the use of colistin in animal production should be considered as a last resort treatment only. Thus, to overcome the economic losses, which would result from the restriction of use of colistin, especially for prophylactic purposes in PWD control, we believe that an understanding of the factors contributing to the development of this disease and the putting in place of practical alternative strategies for the control of PWD in swine is crucial. Such alternatives should improve animal gut health and reduce economic losses in pigs without promoting bacterial resistance. The present review begins with an overview of risk factors of PWD and an update of colistin use in PWD control worldwide in terms of quantities and microbiological outcomes. Subsequently, alternative strategies to the use of colistin for the control of this disease are described and discussed. Finally, a practical approach for the control of PWD in its various phases is proposed.
\end{abstract}

Keywords: Post-weaning diarrhea, Pigs, E. coli, Colistin, Resistance, Alternatives

\section{Background}

Post-weaning diarrhea (PWD) due to Escherichia coli is an economically important disease in pig production worldwide, affecting pigs during the first 2 weeks after weaning and characterized by sudden death or diarrhea, dehydration, and growth retardation in surviving piglets $[1,2]$. Furthermore, many stress factors associated with the weaning period, such as removal from the sow, dietary changes, adapting to a new environment, mixing of pigs from different farms and histological changes in the small intestine, may negatively affect the response of immune system and lead to an intestinal gut dysfunction

\footnotetext{
*Correspondence: mohamed.rhouma@umontreal.ca

1 Department of Pathology and Microbiology, Faculty of Veterinary

Medicine, University of Montreal, 3200 Sicotte Street, Saint-Hyacinthe, QC

J2S 2M2, Canada

Full list of author information is available at the end of the article
}

in pigs [3-5]. Post-weaning diarrhea is usually associated with proliferation of enterotoxigenic E. coli (ETEC) $[2,6]$. This pathotype is characterized by the production of enterotoxins and adhesins, both essential for disease development [7], the predominant adhesins in PWD being F4 and F18 [6, 8]. Small intestinal adhesion and subsequent colonization by ETEC in pigs is mediated by F4 or F18 specific receptors, the existence and function of these receptors being crucial to determine the susceptibility of pigs to ETEC infections [7]. The predominant serogroup of ETEC associated with PWD in pigs worldwide is O149, commonly in the combination O149: LT: STa: STb: EAST1: F4ac [2]. Colistin, a polymyxin antibiotic produced by Paenibacillus polymyxa var colistinus [9], is widely used for the control of PWD in pigs [10]. However, in humans this antibiotic is now considered as the last therapeutic option for the treatment of infections 
caused by multidrug-resistant Gram-negative bacteria (MDR-GNB) such as Pseudomonas aeruginosa, Acinetobacter baumannii, Klebsiella pneumoniae and Enterobacter species [11, 12].

On the other hand, in the last several years, studies have reported the isolation of colistin-resistant $E$. coli from pigs [13, 14], the proportion reaching 35\% in some countries [15]. Until recently, resistance to colistin had only been associated with non-transferable genome mediated mutation. However, in 2015, a stable plasmidmediated gene, $m c r-1$, encoding a phosphoethanolamine transferase conferring resistance to colistin was identified in certain GNB, such as E. coli and Salmonella, isolated from various origins including farm animals, raw meat and humans, in several countries [16-18]. The discovery of a mechanism for horizontal transfer of colistin resistance, and hence the potential for interspecies transfers, gave rise to a strong reaction in the scientific community regarding the potential reduction of colistin effectiveness in human medicine [19]. Food producing animals, and in particular pigs, have been singled out as the most potential reservoirs for spread and amplification of colistin resistance [19]. Thus, scientists and regulatory agencies such as the European Medicine Agency (EMA) have recommended reducing the use of colistin in animal production and to restrict its use to the treatment of sick animals as a last resort option [20]. In addition, several studies have reported coexistence of the $m c r-1$ gene with genes encoding the production of extended-spectrum $\beta$-lactamase (ESBL) and carbapenemase enzymes [21-23]. This constitutes an additional degree of concern about the risk of spread of resistance against antimicrobials of very high importance in human medicine. Furthermore, a high prevalence of ESBL-positive E. coli isolated from PWD piglets has been reported [24]. Taken together, these findings underline the need to better understand PWD risk factors and to find alternatives to antimicrobials and particularly to colistin in pigs for the control of PWD in order to manage antimicrobial resistance and maintain at the same time livestock productivity. Hence, the aim of the present review was to provide an overview of risk factors of PWD as well as an update of information on the extent of colistin use in PWD control worldwide in terms of quantities and microbiological outcomes. In addition, alternative strategies to the use of colistin for the control of this disease are described and discussed. Finally, a practical approach is proposed for the control of the PWD in its various phases.

The prevalence of colistin resistance in pigs and the possible link between colistin pharmacokinetic/pharmacodynamic (PK/PD) and emergence of resistance in Enterobacteriaceae in swine, as well as the aspects that should be considered to ensure judicious use of colistin in swine production, have been investigated in our last two reviews $[18,25]$.

\section{Search strategy and selection criteria}

Articles published in peer-reviewed journals were searched in the international online databases PubMed, Web of Science, and Scopus. The studies were selected based on language (English or French) and accessibility to the full manuscript version. Literature was retrieved through an electronic search, starting from 1980 to the present. Relevant scientific papers were identified using the keyword combinations (piglet OR swine OR pig OR weaned OR sows AND (post-weaning diarrhea), (postweaning), (E. coli), (colistin), (colistin resistance), (colistin use), (colistin indications), AND (pig OR swine OR weaned pigs OR antibiotics in pigs OR colistin in pigs OR E. coli in pigs OR post-weaning diarrhea OR weanling diet in pigs AND (feed strategies) OR (alternatives measures) OR (alternatives to antibiotics) OR (preventive strategies) OR (additives). All searches were performed from September to November 2016. In total, 389 nonduplicate articles were found. After applying the inclusion and exclusion criteria, 271 citations were considered potentially eligible for inclusion in this review.

\section{Risk factors for post-weaning diarrhea in pigs}

Post-weaning diarrhea is an economically important enteric disease in pigs due to financial losses [1]. This disease occurs most frequently within the 2 weeks after weaning and is characterized by a profuse diarrhea, dehydration, significant mortality and loss of body weight of surviving pigs [2]. Mortality associated with this disease may reach $20-30 \%$ over a 1 - to 2-month time span among infected weaned pigs during acute outbreaks of PWD [1].

PWD is a multifactorial disease where the exact cause has not yet been identified [26] (Fig. 1). The occurrence of PWD in pigs involves interactions between the sow, piglet, environment, ETEC bacteria and livestock management [27].

\section{Predisposing factors}

Post-weaning diarrhea is usually associated with the proliferation of one or more strains of $\beta$-hemolytic ETEC in the small intestine of pigs, in particular those that express fimbrial adhesins F4 (K88) or F18 [2]. Thus, small intestinal epithelial cell adhesion and subsequent colonization by ETEC is mediated by F4- or F18-specific receptors (F4R or F18R), the existence and function of which are crucial in determining the susceptibility of pigs to ETEC infection $[2,7]$. The genetic predisposition of the pig is primordial for the development of PWD [28].

In addition, conditions related to pregnancy and parturition of the sow such as litter size, parity, and 


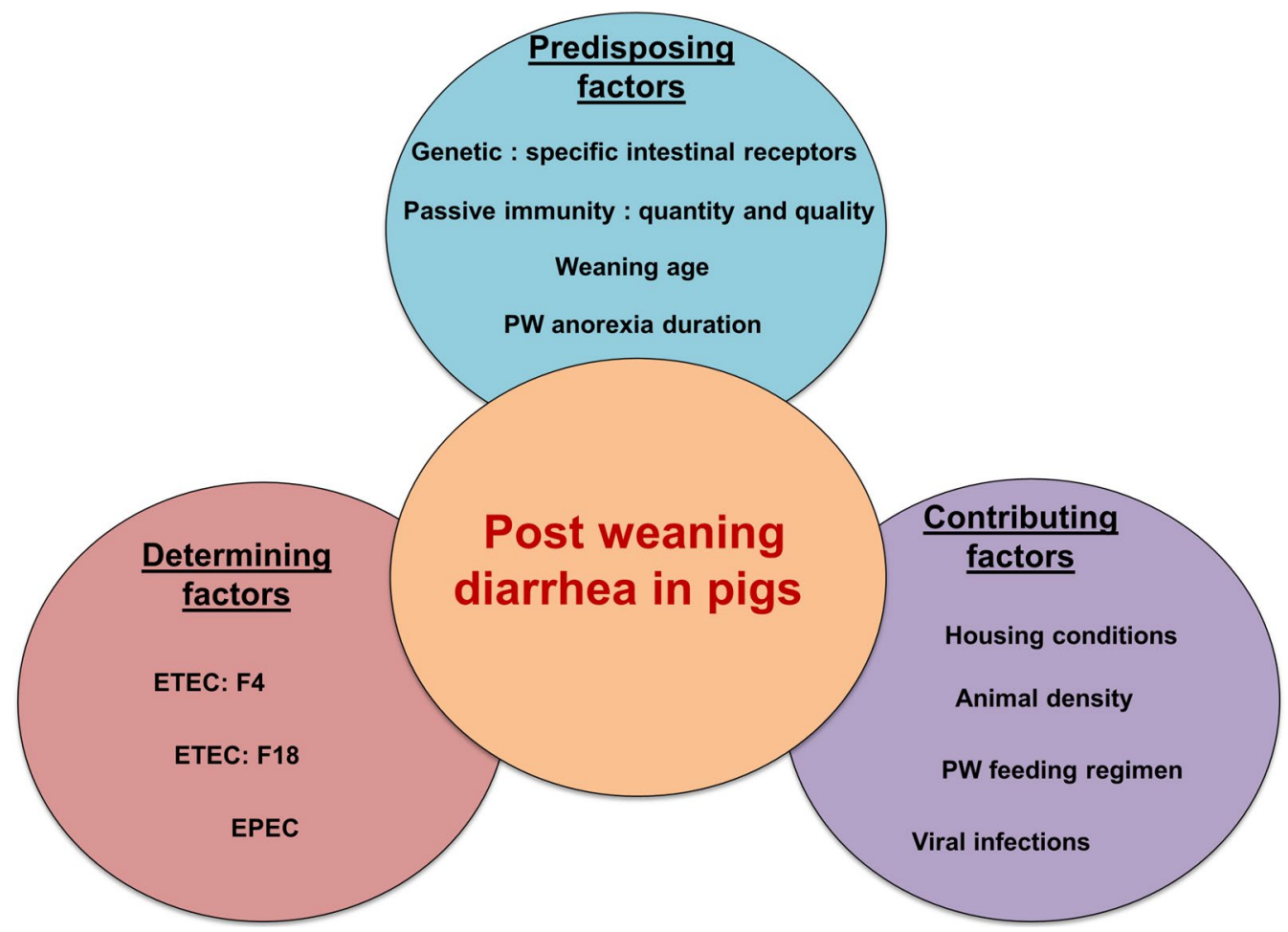

Fig. 1 The multifactorial genesis of post weaning diarrhea (PWD) in pigs involves interaction between predisposing, contributing and determining factors. PW Post weaning, ETEC enterotoxigenic Escherichia coli, EPEC enteropathogenic Escherichia coli

postpartum dysgalactia syndrome are significant in the predisposition of piglets to microbial infection [27, 29]. The sow placenta is not permeable to maternal immunoglobulin transport and therefore newborn piglets acquire maternal immunoglobulin from colostrum during the first 24-48 h of life [5]. It was reported that weaning age and pre-weaning health play a key role in the onset of PWD [30]. Moreover, the post-weaning period is a critical phase in the pig's life when the intestinal immune system is immature, and the sow milk removal, and consequent discontinuation of nutritive intake of the IgA present in this milk, contributes to increase susceptibility of pigs to microbial infections [31]. Indeed, unlike other food animals, the sow's milk is particularly rich in IgA compared to colostrum [32]. Studies investigating the profitability of weaning pigs at an early age, before 21 days, have further encouraged moving away from this practice to weaning pigs no earlier than 26 days of age to reduce the occurrence of PWD [30,33]. In the European Union (EU), many pig producers wean piglets at 21 days of age. However welfare legislation encourages weaning no earlier than 28 days of age in the absence of cleaned housing sections to ensure that healthy pigs are transferred into nursery accommodation [34]. Moreover, studies suggest that increasing weaning age reduces stress associated with this period and allows pigs to have a more mature gastrointestinal tract and become increasingly familiar with solid feed during lactation with an improvement in growth performance and in immune response [34, 35].

Feed intake is usually reduced initially after weaning and the pig may develop anorexia of variable duration and extent between farms, depending on livestock management and the nature of the feed [36]. Madec et al. [30] reported that the low feed intake over the first week after weaning is strongly correlated with the risk of disease occurrence over the post-weaning period. Underfeeding during weaning reduces growth performance of pigs, and contributes to intestinal inflammation and adversely affects villous height and crypt depth [3]. This morphological disruption of the intestinal mucosa promotes the creation of an ideal environment for the multiplication of bacteria such as $E$. coli and allows toxins and bacteria to cross the epithelium as a result of this inflammation [37] (Fig. 2).

\section{Contributing factors}

Housing factors, population density, parity segregated production and the feeding regimen after weaning play a role in the development of PWD [38]. 


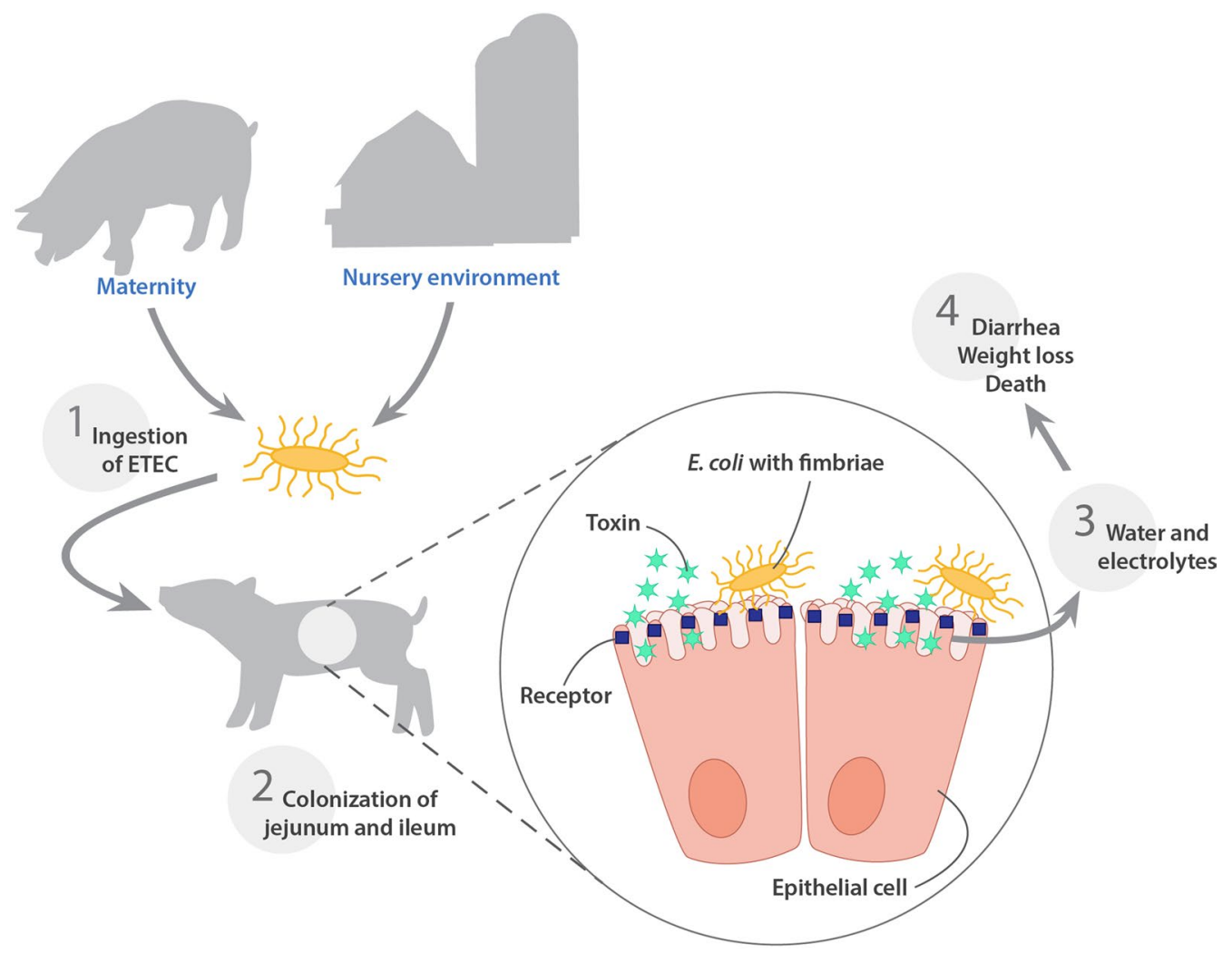

Fig. 2 Schematic representation of the steps involved in the pathogenesis of post weaning diarrhea in pigs

It is beyond the scope of this review to discuss in detail all the ideal conditions for pig housing during the post-weaning period, but to highlight the most important, as reviewed by Le Dividich and Herpin [39], it is essential to provide the correct environmental temperature, $26-28{ }^{\circ} \mathrm{C}$, to maintain pigs in their thermo-neutral zone. Chilling reduces intestinal peristaltic activity and consequently increases bacterial colonization, and low temperatures in weaner facilities appears to be responsible for a more severe course of PWD [40]. Also, it has been shown that automatic temperature control in the weaners housing reduces considerably the prevalence of PWD [38]. Wathes and Whittemore [41] reviewed several recommendations to prevent pig diseases by appropriate housing and environmental management. These approaches involve avoiding drafts while removing moisture and gases using adequate ventilation. Most often, flat decks are used instead of soiled bedding for weaned piglets; however it was reported that this practice is accompanied by more tail and belly lesions among pigs [42]. Moreover, the removal of manure and soiled bedding on a regular basis is also important to reduce the microbial load on farms.
A contradiction was found in the scientific literature concerning the impact of herd size on the prevalence of PWD in pigs. Indeed, Laine and collaborators reported that in Finland, the increase in pig's herd size was associated with a higher risk of PWD in pigs [38]. While, in Canada, Amezuca et al. [43] reported that PWD occurred on a variety of farm types and sizes. However, a link between stocking density and PWD was described in pig's farms in some countries [30, 44]. Mixing piglets from different farms is a common practice in pig husbandry, particularly at weaning. This mixing can result in fighting as the pigs strive to establish dominance relationships, with most aggressive interactions being typically shown during the first few hours after grouping [45]. It has been reported that the hierarchical behaviour among pigs leads to very significant differences in food and water consumption on farms [46]. Production based on segregated sow parities was proposed as a solution to reduce the impact of the social hierarchy. This system of grouping according to the sow's farrowing rank reduces disease challenge by reducing variation in the immune status of the piglets [47].

It was shown that the prevalence of PWD was higher on farms that fed weaned piglets only twice a day with 
a restricted amount of feed than on farms that provided more than two meals per day with or without feed restriction [38]. In addition, Amezuca et al. [43] reported that the occurrence of PWD was greater with pelleted feed and inadequate feeder space per piglet in the pen.

A previously mentioned, PWD is a complex disease that may result from interaction between several infectious agents. However, most epidemiological studies have focussed on monitoring the effect of only one pathogen in the occurrence of this disease, and there is inadequate information concerning other relevant enteric pathogens such as viruses and parasites. Some investigations of mixed infections in PWD showed that rotavirus was considered to be an important enteric pathogen in weaned piglets with a prevalence of $77.5 \%$, followed by $E$. coli, coccidia, sapovirus and Cryptosporidium par$v u m$ with prevalence of $55,10,2.5$ and $2.5 \%$ respectively [48]. In addition, infection by the porcine reproductive and respiratory syndrome virus (PRRSv) results in an impairment of the immune response of piglets, permitting ETEC to cause a septicemia leading to death [49]. However, these data were reported more than 10 years ago and are unlikely to reflect the current epidemiologic situation.

\section{Determining factors}

ETEC is the most common cause of PWD in pigs. This pathotype is characterized by the production of enterotoxins and adhesins, both essential for disease development. Enterotoxins produced by ETEC may be heat stable $[\mathrm{STa}, \mathrm{STb}$, or enteroaggregative $E$. coli heat stable enterotoxin 1 (EAST1)] or heat labile (LT) [2]. Enterotoxin genes are on plasmids of ETEC bacteria and act on the intestinal epithelium of pigs [7].

In pigs, the most frequently found fimbrial adhesins of ETEC are K88 (F4), K99 (F5), 987P (F6), F41, and F18 [40]. F4-positive and F18 ETEC (ETEC: F4 and ETEC: F18) strains represent the major cause of PWD in pigs. F4 are flexible fimbriae that occur as the F4ab, F4ac, or F4ad variant, the F4ac variant being by far the most important type encountered in PWD [50]. The F4 fimbriae mediate bacterial attachment to F4 receptors (F4R), present on the small intestinal brush borders of villous enterocytes allowing ETEC to survive and persist in the small intestine and cause diarrhea [51]. Thus, attachment of ETEC to the pig intestinal mucosa is a crucial step in the pathogenesis and the initiation of PWD. Two antigenic variants of F18 fimbriae exist: F18ab (F107) and F18ac (2134P and 8813). F18ac is commonly associated with ETEC causing PWD, whereas F18ab is often involved in oedema disease [52]. No cross protection between F18ab and F18ac was observed on vaccination against F18 variants [53]. A nonfimbrial adhesin identified as AIDA (adhesin involved in diffuse adherence) has been observed to be associated with ETEC strains recovered from pigs with PWD [54]. In this study, $50.0 \%$ of isolates were ETEC-aid $A^{+}$. Moreover, it has been demonstrated that the expression of AIDA by a diarrheagenic E. coli strain (AIDA-I ${ }^{+}$, $\mathrm{STb}^{+}$) was essential for pig's intestinal colonization and for in vitro bacterial autoaggregation and biofilm formation [55].

Porcine pathogenic E. coli involved in PWD typically belong to serogroups O8, O138, O139, O141, O147, O157 and O149, the latter being the predominant serogroup in most countries [56, 57]. The most implicated virotype in PWD is ETEC: LT: STb: F4 [6]. However, O serogroup and virulence gene patterns vary from region to region and over time [2].

Pathogenesis of porcine enteric colibacillosis has been reviewed extensively elsewhere [7, 40, 57]. Indeed, piglets ingest ETEC found in their environment, especially derived from mammary glands of their mother and from the farrowing room or from the pen environment on arrival in the nursery (Fig. 2). These ETEC originate from the gut of piglets with ETEC diarrhea, or subclinical carrier animals at the farm [57]. ETEC bacteria adhere to pig's small intestinal epithelium, causes an increase of water and electrolytes secretion into the intestinal lumen generated by the release of enterotoxins, and alter the functions of enterocytes by increasing secretion and reducing absorption [7]. Excessive secretion of electrolytes and water leads to dehydration, metabolic acidosis, osmotic diarrhea and possible death [28, 58-60] (Fig. 2). It has been widely reported in the scientific literature that ETEC challenge in pigs was not associated with significant macroscopic lesions or morphological changes in the intestinal mucosa resulting from the toxic activity of ETEC enterotoxins [57, 61, 62]. However, other studies have reported that the necropsy of challenged pigs with ETEC or naturally infected animals, has revealed several lesions such as; dehydration, dilation of the stomach and the small intestines, gastric infarcts in the mucosa of the stomach, and congestion of the mucosa of both the small intestine and the colon [57, 63]. Furthermore, ETEC infections in pigs may also result in a shock syndrome with hemorrhagic gastroenteritis, congestion, renal hemorrhage, and thrombi in the mucosa of the stomach and small intestine [64-66]. Moreover, intestinal ETEC infections in pigs might be associated with secondary septicemia [66] and inactivation of the hemolysin structural gene $(h l y A)$ of an ETEC: F4 challenge strain did not decrease the incidence of this septicemia in orally challenged gnotobiotic piglets [66]. Thus, macroscopic lesions of shock syndrome and septicemia related to ETEC infection in the post weaning period in pigs are probably the consequence of the rapid release of bacterial 
LPS from the pig's intestine into the systemic circulation [57]. On the other hand, microscopically, ETEC challenge in pigs has been associated with a greater villous atrophy and a large crypt depth reduction in all segments of the intestine of challenged animals [67].

ETEC isolates from pig farms with PWD may show a high frequency of resistance to multiple antimicrobials $[1,68]$. Nevertheless, there is no indication that drug resistance enhances the virulence of ETEC, although virulence genes are sometimes associated with drug resistance genes [56].

Porcine attaching and effacing E. coli (AEEC) induce intestinal lesions similar to those produced by enteropathogenic E. coli (EPEC) in humans, and this pathotype is found in pigs with PWD [40]. These E. coli carry the eae gene encoding a $94 \mathrm{kDa}$ outer membrane protein (intimin) which is responsible for intimate attachment to epithelial cells. However, the pathogenic significance of porcine EAE positive isolates in weaned pigs is still unknown [2]. Furthermore, identification of porcine EPEC is difficult and many veterinary diagnostic laboratories do not routinely screen for this pathotype of E. coli, isolates of which do not usually possess any of virulence factors of classic PWD or oedema strains [40].

\section{Extent of colistin use in weaned pigs worldwide}

The global demand for colistin in agriculture is expected to reach 16,500 tons by the year 2021, this being one of the least expensive classes of antimicrobials available in veterinary medicine in some countries [17]. Thus, the pricing structure makes colistin particularly attractive for use in pig production. Since the inception of its clinical use in 1960, colistin has been used in pig production in many countries for the treatment and prevention of digestive disorders caused by Enterobacteriaceae, and even sometimes for growth promotion over long periods, to improve growth rate and feed conversion efficiency in pigs $[18,69,70]$. In certain countries such as Canada, where colistin has not been approved for use in pigs, a rapid increase in resistance of ETEC to a wide range of antimicrobials has prompted the use of colistin in weaned pigs under the veterinarian's responsibility [71]. However, current data on the total quantities of colistin used in pigs worldwide have been difficult to obtain accurately [70]. Some data, for example in Denmark, indicate that the use of colistin for the treatment of sows increased between 2002 and 2008 [72]. Of the two forms of colistin commercially available, colistin sulfate (CS) and colistin methanesulphonate sodium (CMS), and only CS is approved in pig production in some countries [18]. Usually it is administered orally in the drinking water at the dose of 50,000 IU/kg body weight every $12 \mathrm{~h}$ for 3 or 5 days [25]. Colistin is mostly used in monotherapy in pigs, although it may be combined with other antimicrobials, such as amoxicillin, for the treatment of PWD [25, 73].

\section{Colistin use in post weaning diarrhea on farms}

Due to its activity directed against GNB, colistin is widely used for the control of PWD in pigs [10,74]. Two surveys conducted in pig farms in Belgium, in 2006 [73], and 2012 [74] confirmed that colistin was the most frequently used antimicrobial for the control of PWD, being mostly used prophylactically. However, colistin was underdosed in 90 and $53 \%$ of the cases, in the first and the second survey respectively. In Germany, it was reported that intestinal diseases in weaners were commonly treated with colistin, pigs being treated 9.7 days (median) per 100 days with this antibiotic, although tetracycline and tylosin were also used in approximately equal amounts [75]. In a study in France, it was reported that $90 \%$ of pig farms used colistin during the post-weaning period [10]. In Vietnam, a survey conducted on pig farms representing three different animal production systems (farm household, semiindustrial and industrial) showed that colistin was the most commonly used antimicrobial for prevention and therapy of gastrointestinal disorders in pigs [76].

It has been reported that China is the country with the greatest use of colistin in pigs worldwide [17], although we did not find any reports in the literature on surveys of colistin use in this country in the post-weaning period. Overall, colistin is widely used in the management of the PWD, with a lot of differences between countries in terms of quantities used and modality of administration [18].

\section{Microbiological and clinical outcomes of colistin use in controlled conditions}

Most of the recent studies conducted in pigs have used CS in experimental conditions for the control of diarrhea in the post-weaning period (Table 1). Several of these studies were performed to examine the effectiveness of alternative substances to colistin in the treatment of PWD $[77,78]$.

It is often difficult to compare results between studies, because of the variability in the dose of CS used, treatment duration, and the experimental design of the study. In Table 1 , we have summarized the main results reported in the literature concerning fecal E. coli shedding and pig performance following oral CS treatment. Several studies have also followed histological (i.e. intestinal mucosa morphology) and biochemical (e.g. D-lactate, nitric oxide, xylose, etc.) parameters subsequent to CS use in the post-weaning period in pigs [78, 79]. In order to evaluate the effect of colistin on fecal $E$. coli shedding, bacterial quantification was performed 
Table 1 Microbiological and clinical outcomes of monotherapy with colistin in pigs

\begin{tabular}{|c|c|c|c|c|c|c|}
\hline Bacterial agents/condition & Dose per day & $\begin{array}{l}\text { Duration } \\
\text { (days) }\end{array}$ & Sample type & $\begin{array}{l}\text { Reduction in E. coli } \\
(\log c f u / g)^{c}\end{array}$ & $\begin{array}{l}\text { Performance } \\
\text { (ADG, g/day) }\end{array}$ & References \\
\hline \multirow[t]{2}{*}{ E. coli K99/experimental PWD } & $300 \mathrm{mg} / \mathrm{kg}$ of diet & 7 & Ileum & 6.55 & $122^{b}$ & {$[154]$} \\
\hline & & & Cecum & 6.63 & & \\
\hline \multirow[t]{2}{*}{ E. coli K99/experimental PWD } & $300 \mathrm{mg} / \mathrm{kg}$ of diet & 10 & Ileum & 2.3 & $128^{\mathrm{a}}$ & [77] \\
\hline & & & Cecum & 3.2 & & \\
\hline Weaned pigs (clinically healthy) & $200 \mathrm{mg} / \mathrm{kg}$ of diet & 7 & N/A & N/A & $229^{a}$ & {$[155]$} \\
\hline \multirow[t]{3}{*}{ ETEC mixture/experimental PWD } & $200 \mathrm{mg} / \mathrm{kg}$ of diet & 21 & Ileum & 1.54 & $292^{b}$ & [156] \\
\hline & & & Cecum & 1.65 & & \\
\hline & & & Colon & 0.65 & & \\
\hline ETEC mixture/experimental PWD & $\begin{array}{l}2.5 \text { mg/animal (Oral- } \\
\text { Water) }\end{array}$ & 21 & Fecal samples & 3 & $283^{b}$ & [78] \\
\hline \multirow[t]{3}{*}{ Weaned pigs (clinically healthy) } & $40 \mathrm{mg} / \mathrm{kg}$ of diet & 14 & Ileum & N/A & $142.2^{\mathrm{a}}$ & [81] \\
\hline & & & Cecum & & & \\
\hline & & & Colon & & & \\
\hline E. coli K88/experimental PWD & 4.8 mg/kg (Oral-Water) & 5 & Fecal samples & 4 & $214^{\mathrm{a}}$ & [28] \\
\hline E. coli K88/experimental PWD & 9.6 mg/Kg (Oral-Water) & 5 & Fecal samples & 4 & N/A & {$[28]$} \\
\hline Weaned pigs (clinically healthy) & $172.8 \mathrm{mg} / \mathrm{kg}$ of diet & 14 & Fecal samples & $4.5^{d}$ & $\mathrm{~N} / \mathrm{A}$ & {$[80]$} \\
\hline
\end{tabular}

$P W D$ post-weaning diarrhea, $A D G$ average daily weight gain, N/A not available, ETEC enterotoxigenic Escherichia coli

${ }^{\text {a }}$ Not statistically significant compared to the control group

b Statistically significant compared to the control group

c Reduction compared to the control group

${ }^{d} \log$ cfu of Enterobacteriaceae/g

in most studies using culture methods [28, 77], whereas other studies used real-time PCR [79, 80]. Furthermore, the oral use of a high dose of colistin in healthy piglets was not associated with a major perturbation in the pig gut microbiota as demonstrated by a high-throughput sequencing method [80].

Although colistin has been used in some studies to promote animal growth, data were not conclusive to support the effectiveness of this practice [81]. In this study, no difference was observed between the CS treated and the control group in terms of average daily gain per day (ADG/day) [81]. Also, the economic benefits of antimicrobial growth promotion in modern farms have been questioned [82], the benefit of this use being associated with poor hygiene on farms.

\section{Alternative strategies to colistin for post-weaning diarrhea control}

Reduced colistin usage in livestock and particularly in swine is highly promoted worldwide and is required in Europe as a public health measure to reduce colistin resistance spread, and to prevent the loss of polymyxins effectiveness in human medicine [25]. Furthermore, concurrent treatment with colistin in piglets was associated with the isolation of resistant bacteria from the earliest days of treatment [28]. Almost all studies conducted on isolates from pigs worldwide to screen $\mathrm{mcr}$ - 1 gene presence in enterobacterial species reported that colistin resistant isolates harboring this gene also showed resistance to one or several classes of antimicrobials conventionally used in swine such as: aminoglycoside, sulphonamide, trimethoprim, tetracycline, quinolone, lincosamide, $\beta$-lactam, and third generation cephalosporin [83-86].

However, to ensure swine welfare, productivity and reduced mortality associated with PWD, alternatives to colistin and other antimicrobials, especially those of critical importance for human health, are essential in pigs. There is a major debate over the terminology 'alternative to antibiotics' because we do not propose substances with antibacterial activity but rather substances that act on bacteria indirectly, either by stimulating the host immune system, by the release of substances that have antibacterial activity or by improving the host gut health and consequently growth performance [87]. Thus, we will use the terminology «strategies» or «measures» to describe alternatives to antimicrobials. Due to the multifactorial etiology of PWD, finding case-specific preventive measures against this disease is a challenge for both researchers and veterinarians. 
Here we give an overview of these preventive strategies, focusing on the most practical and promising ones for the control of PWD in pigs.

\section{Preventive measures}

In the literature, many alternatives to antimicrobial usage in food-producing animals have been reported and discussed [87-90]. The most promising way to mitigate the development of colistin resistance is to reduce the use of antimicrobials at the farm level (Table 2). There are documented relationships between housing conditions and incidence of PWD in pig herds; Madec et al. [30] claimed that prevention of PWD disorders could be based solely on the control of zootechnical conditions. Moreover, stocking density reduction could be considered as a paramount strategy to decrease occurrence of PWD as well as other diseases in pigs [91]. Thus, improvement of breeding conditions in pig farms is a crucial measure to reduce the susceptibility of animals to microbial infections and consequently to reduce the use of antimicrobials in pig production [28]. The management strategies around weaning should focus on measures that avoid any kind of stress for pigs. These measures include preventing the spread of infection, providing the pigs with good thermal comfort, giving them adapted feed and allowing access to this feed for all pigs.

Considerable research has been performed into developing diets for weaners and there is now a range of high quality diets that are readily digested by the early-weaned pig [31]. The main purposes of these diets are to achieve

Table 2 Preventive strategies to reduce the use of antimicrobials during the post-weaning period

\begin{tabular}{|c|c|c|c|}
\hline Strategies & Benefits & Limitations & References \\
\hline \multirow{4}{*}{$\begin{array}{l}\text { Control of housing environment } \\
\text { and improved biosecurity }\end{array}$} & Very effective approach & Significant cost & \multirow[t]{4}{*}[28,30]{} \\
\hline & Significantly reduces PWD occurrence & Extreme weather conditions in some countries & \\
\hline & Reduces the use of antimicrobials in farm & $\begin{array}{l}\text { Acceptability of farmers to change some man- } \\
\text { agement techniques }\end{array}$ & \\
\hline & Sustainable approach & Financial support is required & \\
\hline \multirow[t]{2}{*}{$\begin{array}{l}\text { Diet management (reducing the } \\
\text { amount of soybean) }\end{array}$} & $\begin{array}{l}\text { Reduces the severity and frequency of PWD and } \\
\text { oedema disease }\end{array}$ & $\begin{array}{l}\text { Growth retardation } \\
\text { Increase production }\end{array}$ & \multirow[t]{2}{*}{ [31] } \\
\hline & $\begin{array}{l}\text { Reduction of histological changes in intestinal } \\
\text { crypt and villi }\end{array}$ & Considerable controversy between studies & \\
\hline \multirow{3}{*}{$\begin{array}{l}\text { Communicative advisory tools for } \\
\text { pig farmers }\end{array}$} & Improving breeding management & Requires a lot of field work & \multirow[t]{3}{*}{ [94] } \\
\hline & $\begin{array}{l}\text { Farmers feel concerned by the problem of antibi- } \\
\text { otic resistance }\end{array}$ & $\begin{array}{l}\text { Farmers worried mostly about infectious diseases } \\
\text { and financial issues }\end{array}$ & \\
\hline & Raised awareness and responsibility & Financial bonus is required & \\
\hline \multirow[t]{2}{*}{$\begin{array}{l}\text { Laboratory diagnosis to confirm } \\
\text { etiology of PWD }\end{array}$} & $\begin{array}{l}\text { Avoid the use of antimicrobials to treat viral } \\
\text { diarrhea }\end{array}$ & Significant cost & \multirow[t]{2}{*}{ [95] } \\
\hline & Allows an appropriate choice for antibiotics & Lack of rapid diagnostic techniques & \\
\hline \multirow[t]{2}{*}{ Policy measures } & $\begin{array}{l}\text { Reduce the sale and the use of antimicrobials on } \\
\text { farm }\end{array}$ & Requires penalties & \multirow[t]{2}{*}{ [94] } \\
\hline & Reduce self-medication & Financial bonus is required & \\
\hline \multirow{3}{*}{$\begin{array}{l}\text { Immunoprophylaxis: Live attenu- } \\
\text { ated and live wild type avirulent } \\
\text { E. coli }\end{array}$} & Specific protection against ETEC: F4 or F18 & $\begin{array}{l}\text { Interference with the lactogenic immunity of } \\
\text { piglets }\end{array}$ & \multirow[t]{3}{*}{ [97] } \\
\hline & Easy to administer on farms (drinking water) & $\begin{array}{l}\text { Absence of cross-protection between F18ab } \\
\text { strains }\end{array}$ & \\
\hline & $\begin{array}{l}\text { Reduces antimicrobial use in the PW period } \\
\text { Marketed in swine }\end{array}$ & Limited availability in some countries & \\
\hline \multirow[t]{3}{*}{$\begin{array}{l}\text { Immunoprophylaxis: Subunit vac- } \\
\text { cines (purified F4 fimbriae) }\end{array}$} & A powerful oral immunogen & $\begin{array}{l}\text { The proposed immunization procedure required } \\
\text { large quantities of } \mathrm{F} 4\end{array}$ & \multirow[t]{3}{*}{ [8] } \\
\hline & Leads to a specific mucosal immune response & $\begin{array}{l}\text { Antigen degraded by the } \mathrm{pH} \text { of the stomach and } \\
\text { by digestive enzymes }\end{array}$ & \\
\hline & $\begin{array}{l}\text { Leads to a significant reduction in fecal excretion } \\
\text { of ETEC: F4 }\end{array}$ & $\begin{array}{l}\text { Usually required mucosal adjuvant such as } \\
\text { Cholera toxin }\end{array}$ & \\
\hline \multirow[t]{3}{*}{ Breeding of resistant pigs } & Very effective approach & Expensive process & \multirow[t]{3}{*}{ [2] } \\
\hline & $\begin{array}{l}\text { Greatly reduces the total amount of antimicrobi- } \\
\text { als used on farms }\end{array}$ & Lack of techniques for a large-scale selection & \\
\hline & Reduces the selection pressure & Development of other adherence mechanisms & \\
\hline
\end{tabular}


high post-weaning feed intakes and minimize duration of post-weaning anorexia and consequently growth retardation. It has been reported that the presence of some ingredients in the feed for weaners, such as soybeans, seems to favor the occurrence of PWD [92]. This could be due to the presence of trypsin inhibitors or antigens inducing a localized immune response [2]. Furthermore, it was shown that soya bean meal (SBM) reduced duodenal specific activities of most intestinal enzymes and increased crypt depth in pigs [93]. Thus, such ingredients should be avoided in feed of early-weaned pigs. In addition, feeds with decreased protein content and the addition of organic acid to reduce gastric $\mathrm{pH}$ were found to decrease E. coli colonization and to minimize PWD prevalence [31].

The scientific community increasingly recognizes the importance of communication and awareness among farmers in relation to antimicrobial resistance, as reflected by the growing number of publications in this area in recent years $[18,94]$. This suggests that farmers' perceptions, and the factors affecting their behaviour, need to be better understood if effective measures associated responsible and prudent use of antimicrobials are to be implemented successfully.

Moreover, effective diagnostic tools are essential for veterinarians to confirm the bacterial etiology of PWD and to determine the antimicrobial susceptibility of the identified bacterial strain. The laboratory diagnosis is particularly important in PWD to avoid the inappropriate use of antimicrobials. DNA-based molecular detection methods such multiplex PCR based on the detection of ETEC virulence genes are rapidly becoming part of the routine laboratory diagnosis of PWD, and these genes are used as a biomarkers of ETEC strain [7, 58].

In several countries, implementation of financial penalties for high antimicrobial users is proposed as a method to reduce antimicrobial usage and pig farmers would receive a financial bonus when they use alternative methods or when they greatly reduce antimicrobial use on their farms [94]. Vaccination seems to be an effective approach to reduce the occurrence of PWD and to reduce infection pressure and increase immunity in the pig population [2]. Several studies conducted in pigs confirm a reduction of antimicrobial usage after vaccination [95]. In fact, vaccination against the porcine proliferative enteropathy caused by Lawsonia intracellularis reduced the need for therapeutic oxytetracycline administration in Danish pigs [96]. Live attenuated and wild type avirulent $E$. coli vaccines appear to be promising for the control of ETEC infections and live vaccine against ETEC: F4, is now available in Canada and Europe [97]. This vaccine is added to the drinking water and recommended for the vaccination of healthy weaned pigs of 17 days or more. Clinical studies confirmed that administration of this vaccine significantly reduced intestinal colonization by virulent ETEC: F4 and the accumulation of fluid in the intestines after an experimental challenge [98]. The immunity in piglets begins 7 days after oral vaccination, however, since PWD caused by ETEC: F4 occurs shortly, in the first week, after weaning, an immune trough may exist in the first days after weaning during which the pigs are not protected [97]. Thus, the time of the administration of this vaccine should be adjusted. In addition, clinical trials of vaccination against ETEC: F18 has been carried out in pigs. Genetically susceptible pigs were vaccinated orally on three consecutive days, beginning 10 days before weaning with a live F18ac-positive E. coli vaccine [53]. In this study, a significant rise in F18ac-specific serum IgA and a 3 Log CFU decrease in fecal shedding of the F18ac-positive challenge strain was observed compared to the unvaccinated group. However, this vaccine did not induce protective immunity against ETEC: F18. On the other hand, it was shown that a minor subunit of F18 (FedF) alone or genetically fused to F4 FaeG subunit or conjugated to $\mathrm{F} 4$ fimbriae induced protective anti-F18 antibodies in pigs [99]. In general, the success of a vaccine against PWD depends largely on the identification of the most prevalent ETEC pathotype present in the farm, resulting in matching of the appropriate protective antigens with the adhesin produced by the ETEC present on the farm, and administering it at the optimal time [7]. For vaccines consisting of live F4 or F18ac-positive $E$. coli, it is often recommended to vaccinate suckling pigs to obtain a strong mucosal immunity production, IgA, before weaning. However, our knowledge is very limited about the effect of maternal antibodies on the survival of these vaccine strains in the intestine of pigs of this age. Also, there is no cross protection against ETEC strains expressing a different fimbria or toxin. Recently, plantbased vaccines for protection of pigs against ETEC were investigated. A rice-based cholera vaccine expressing the choleratoxin (CT) subunit B (CTB) (MucoRice-CTB) was tested in pigs for protection against LT-ETEC infection [100]. CTB-based vaccines can target not only F4-type but also F18-type ETECs, and this vaccine also induced maternal CTB-specific IgG and IgA in the colostrum and milk of sows after farrowing. CTB-specific antibodies were also secreted into the gut lumen of weaned pigs and reduced intestinal loop fluid accumulation upon ETEC challenge, indicating a protective effect of this vaccine against ETEC diarrhea [100]. However, the cost of these vaccines is very high and, unlike open-air farming, the production of transgenic plants for biotherapeutic use is very demanding. Moreover, the procedures for manufacturing and processing of plant-based pharmaceuticals are not well defined. Thus, a large-scale production of these 
vaccines not envisaged, at least in the near future. Current progress in the development of subunit vaccines against ETEC associated with diarrhea in humans and animals has been reviewed extensively elsewhere [97, 101]. However, none of these subunit vaccines has been marketed in swine.

The selection of animals genetically resistant to ETEC F4 and/or F18 is considered as a radical solution to eliminate the PWD in a swine herd. However, progress in this area is very limited or even non-existent. Pigs that are resistant to ETEC: F4 and/or F18 do not express intestinal receptors for these fimbrial types [2]. The expression of these receptors is genetically determined and inherited in a dominant way and the loci controlling F4R and F18R expression are located on separate chromosomes. The gene underlying resistance to F4ab/ac ETEC has been assigned to porcine chromosome 13, whereas the F4ad ETEC receptor is located on another chromosome that was not identified [102]. A PCR-RFLP test has been developed to allow genotyping for F4ab/ac ETEC resistance/susceptibility [103]. Three different genotypes were observed and were identified as resistant (RR), susceptible heterozygote (SR) and susceptible homozygote (SS). However, it cannot be predicted if additional types of adhesive fimbriae or new variants of known types will emerge which could bind to yet unidentified receptors and could cause outbreaks of diarrhea and mortality in the nursery [2]. It is difficult to understand the reasons behind the non-exploration of the genetic breeding for ETEC resistant pigs to reduce economic losses associated with PWD and to reduce the use of antimicrobials on farms. It was shown in an early study that F4 susceptible piglets tend to have better growth performance then F4 resistant ones [104]. Also, heterozygous F4R ${ }^{-}$piglets are not passively protected from infection by ETEC: F4 strains [105].

\section{Feed additives}

In pigs, PWD can be controlled using various preventive strategies without using antimicrobials (Table 3). Feed supplements such as zinc oxide, organic acids, pre-probiotics, synbiotics, dehydrated porcine plasma, antimicrobial peptides, specific egg yolk and bacteriophages [31, $89,106-110]$ have been used in weanling pigs to enhance growth, feed efficiency and to reduce PWD. Here we give an overview of these feed strategies, focusing on the most used practices showing clinical effectiveness in reducing symptoms of PWD and ETEC attachment to enterocytes.

Zinc oxide: it has been shown that the addition of zinc $(\mathrm{Zn})$ as zinc oxide $(\mathrm{ZnO})$ at the levels of $2400-3000 \mathrm{ppm}$ in pig feed was effective in the reducing of PWD and mortality and in improving growth performance in weaned pigs [111, 112]. However, Amezcua and collaborators [1] reported an important proportion of farms with PWD occurrence using high levels of $\mathrm{ZnO}$. Also, several studies reported an increased proportion of $E$. coli isolates resistant to tetracycline and sulfonamides in pigs fed with high zinc doses $[113,114]$. This may explain why antimicrobial resistance persists even in the absence of antimicrobial exposure $[115,116]$. Moreover, the use of high zinc levels in pig feeds has led to heavy metal contamination in the soil, raising environmental concerns [115]. Recently, Bouwhuis et al. [117] reported that organic zinc [zinc methionine $(\mathrm{ZnM})]$ could be used as a substitute for the inorganic zinc $(\mathrm{ZnO})$ in the pig diet. In fact, organic zinc can be supplemented in lower doses (up to $500 \mathrm{mg} / \mathrm{kg}$ feed) compared to $\mathrm{ZnO}$ [117]. In this study, the inclusion of $\mathrm{ZnM}$ resulted in improved faecal scores and the intestinal architecture compared to that observed in pigs supplemented with $\mathrm{ZnO}$.

Organic acids such as citric, fumaric, lactic, propionic, benzoic and formic acids showed beneficial effects in the pig gastrointestinal tract. In fact, the use of organic acids in weaned piglets was associated with a reduction of stomach $\mathrm{pH}$ [118]. With this effect, organic acids generate a hostile gastric environment for bacterial survival. Moreover, organic acids promote the conversion of pepsinogen into pepsin in the stomach of pigs, and promote the activity of this enzyme [108]. On the other hand, decreasing the intestinal $\mathrm{pH}$ is probably not a primary effect of feeding organic acids in pigs. Indeed, Risley et al. [119] reported a non significant decrease in the $\mathrm{pH}$ of the small intestine in 3-week-old weanling pigs fed with a diet supplemented with $1.5 \%$ fumaric or citric acid. Addition of organic acids to weaned pig diets improved growth performance and health [31] as well as the local immunity in the jejunum epithelium [120]. It was reported that regardless of the organic acids used in the feed, these compounds reduced the incidence and severity of diarrhea in pigs, and improved the performance of the treated group compared to that of the negative control group [121].

Prebiotics are selectively fermented components of feed, indigestible by the host animal, that modulate the gut microbiota to benefit host health. Resulting effects include the stimulation of short-chain fatty acid (SCFA) production and the proliferation of bifidobacteria and lactic acid bacteria such as Lactobacillus spp. and Bifidobacterium spp. [122, 123]. Common prebiotics include inulin and oligosaccharides such as galactooligosaccharides (GOS) and fructooligosaccharides (FOS) [124]. Pigs fed with chito-oligosaccharides (COS) showed better overall intestinal health (based on villi height), improved performance (measured by body weight gain and feed conversion ratio) and higher Lactobacillus counts than those found in control pigs or pigs receiving diets 
Table 3 Benefits and limitations of the major alternative feed strategies for the control of post weaning diarrhea (PWD) in pigs

\begin{tabular}{|c|c|c|c|}
\hline Strategies & Benefits & Limitations & References \\
\hline \multirow[t]{4}{*}{ Zinc oxide } & $\begin{array}{l}\text { Inhibition of bacterial adhesion to the intestinal } \\
\text { mucosa }\end{array}$ & High levels increased PWD & \multirow[t]{4}{*}[112,115]{} \\
\hline & Stimulated growth rate & Soil heavy metal contamination & \\
\hline & Maintained intestinal mucosal integrity & Bacterial resistance & \\
\hline & Modulated immune functions & Co-resistance & \\
\hline \multirow[t]{3}{*}{ Organic acids } & Decreased $\mathrm{pH}$ in the stomach & Exact modes of action still unknown & \multirow[t]{3}{*}[108]{} \\
\hline & Improved growth performance & Anti microbial activities is different between & \\
\hline & Reduced PWD & acids & \\
\hline \multirow[t]{4}{*}{ Prebiotics, probiotics and synbiotics } & Improved intestinal health & $\begin{array}{l}\text { Sometimes contradictory studies on their } \\
\text { effectiveness }\end{array}$ & \multirow[t]{4}{*}[127,130]{} \\
\hline & Improved growth performance & \multirow{3}{*}{$\begin{array}{l}\text { Lack of information on the potential synergism } \\
\text { between pre- and probiotics }\end{array}$} & \\
\hline & $\begin{array}{l}\text { Reduced ETEC: F4 attachment to the ileal } \\
\text { mucosa }\end{array}$ & & \\
\hline & Reduced diarrhea & & \\
\hline \multirow[t]{4}{*}{ Spray dried plasma (SDP) } & Improved growth performance & High cost & \multirow[t]{4}{*}[111]{} \\
\hline & Reduced incidence and severity of diarrhea & $\begin{array}{l}\text { Required rigorous control during the prepara- } \\
\text { tion process }\end{array}$ & \\
\hline & Reduced the markers of intestinal inflammation & Potential source of pathogens? & \\
\hline & Maintained mucosal integrity & & \\
\hline \multirow[t]{5}{*}{ Antimicrobial peptides (AMPs) } & Improved growth performance & The pharmacokinetics in vivo is unknown & \multirow[t]{5}{*}[89,139]{} \\
\hline & Decreased diarrhea & \multirow[t]{4}{*}{ Bacterial resistance } & \\
\hline & Reduced the markers of intestinal inflammation & & \\
\hline & Enhance immune function & & \\
\hline & $\begin{array}{l}\text { Cocktails of AMPs might be used to mitigate } \\
\text { selection for resistance }\end{array}$ & & \\
\hline \multirow[t]{3}{*}{ Specific egg yolk antibodies } & Improved growth performance & High cost & \multirow[t]{3}{*}[111]{} \\
\hline & Decreased diarrhea & Antibodies are sometime not specific against & \\
\hline & Maintained intestinal mucosal integrity & the infecting ETEC strains on farms & \\
\hline \multirow[t]{3}{*}{ Bacteriophages } & Reduced E. coli mucosal adhesion & Narrow spectrum of activity & \multirow[t]{3}{*}[144]{} \\
\hline & Maintained intestinal mucosal integrity & Development of bacterial resistance & \\
\hline & Decreased diarrhea & A combination of phages is needed & \\
\hline
\end{tabular}

supplemented with chlortetracycline [125]. Also, fermented ingredients, such as non-starch polysaccharide hydrolysis products of soybean meal (SBM) in weaned pig feed, were found to interfere with attachment of ETEC to enterocytes and were beneficial in maintaining fluid balance during ETEC infection [126]. It was shown that the prebiotic $\beta$-galactomannan ( $\beta \mathrm{GM})$ inhibited the in vitro adhesion of ETEC on the cell surface of porcine intestinal IPI-2I cells, and decreased the mRNA ETECinduced gene expression of pro-inflammatory cytokines such as TNF- $\alpha$, IL-6, GM-CSF and chemokines on intestinal IPI-2I cells [127].

Probiotics such as lactic acid bacteria, Bacillus and yeasts are live microbial feed supplements [122]. Probiotic bacteria have also been shown to produce antimicrobial molecules, such as bacteriocins, and to inhibit the production of bacterial toxins or the adhesion of pathogens to the intestinal mucosa [123]. Several studies demonstrated that pre-treatment with certain probiotics, such as L. rhamnosus, was effective in reducing diarrhea in experimental ETEC: F4 PWD in pigs, possibly via the modulation of the intestinal microbiota, enhancement of intestinal antibody defense, and regulation of production of systemic inflammatory cytokine [128]. Recently, Lane et al. [129] reported that $L$. acidophilus supplementation $(0.2 \%)$ in the weaned pig diet resulted in higher Lactobacillus counts and lower E. coli counts, as well as an increase in ADG and the average daily feed intake in supplemented pigs compared to the basal diet pigs. A Bacillus licheniformis and Bacillus subtilis spore mixture (BLS-mix) was effective in preventing loss of intestinal epithelial barrier integrity after a challenge with ETEC: 
F4 in experimental PWD [130]. In addition, it was shown that the feeding of pigs with live yeast Saccharomyces cerevisiae enhanced their growth and reduced the duration and the severity of PWD caused by ETEC [131]. It has been demonstrated that the administration of a mixture of two probiotics, Pediococcus acidilactici and Saccharomyces cerevisiae boulardii, in the feed of challenged weaned pigs reduced ETEC: F4 attachment to the ileal mucosa in comparison with the group treated with chlortetracycline and tiamulin [103].

Synbiotics refers to a combination of probiotic and prebiotic approaches; it is possible that a prebiotic that confers gastrointestinal health benefits could selectively increase the population and/or activity of probiotics in the gut [132]. Synbiotics can be either complementary or synergistic. Complementary synbiotics consist of a probiotic and a prebiotic selected independently to confer benefits to the host. On the other hand, synergistic synbiotics are comprised of a prebiotic chosen specifically for the selected probiotic to potentiate its effect in the gut [133]. It was shown that the combination of raw potato starch and a probiotic had a beneficial effect on pig growth performance and resulted in a reduction of diarrhea and increased microbial diversity in the gut of weaned pigs challenged with an ETEC: F4 strain [134]. Also, GuerraOrdaz et al. [135] showed that following a challenge of pigs with pathogenic $E$. coli (O149:K91:H10), administration of a prebiotic oligosaccharide, lactulose, in the feed resulted in improved weight gain, increased lactobacilli and the proportion of butyric acid in the colon, and less inflammation due to a reduction of the pig major acutephase protein (Pig-MAP) in serum. Administration of Lactobacillus plantarum in the feed promoted lactobacilli growth, modulated fermentative activity, reduced inflammation, and improved intestinal mucosa function and showed a tendency to reduce diarrhea. The application of a synbiotic diet resulted in the benefits of both diet regimes, thus being an example of a complementary synbiotic [135].

Spray dried plasma (SDP) is a protein rich product obtained from the industrial fractionation of blood from healthy animals [106]. It was shown that addition of SDP to the feed improved growth performance, and protects pigs against ETEC: F4 infection by reducing the intestinal expression of inflammatory cytokines such as TNF- $\alpha$ and interleukin- 8 and maintaining mucosal integrity, and enhancing specific antibody defense [111]. Spray dried plasma (SDPP) of porcine origin has been pinpointed as a potential source for the coronavirus in a recent epidemic of porcine epidemic diarrhea (PED) [136]. Thus, spray-dried chicken plasma (SDCP) has been evaluated as a replacement for SDPP in weaned pigs. Indeed, the effect of SDCP on serum biochemistry, intestinal barrier function, immune parameters, and the expression of intestinal development-related genes in piglets was similar to SDPP [137]. Nevertheless, a study has provided evidence that PED virus is inactivated during the SDPP production process [138].

Antimicrobial peptides (AMPs) are small molecules constituting an important part of the innate immune system. They may present antibacterial, antifungal, antiparasitic, and antiviral activities, and are increasingly of interest as alternatives to classic antibiotics [88]. AMPs such as lactoferrin, cecropin, defensin, plectasin and bacteriocins showed beneficial effects on growth performance, nutrient digestibility, small intestinal morphology and gut microbiota in pigs [89]. Available data on the effect of AMPs on swine health and especially in the control of PWD have been reviewed extensively elsewhere $[89,139]$. Antimicrobial lactoferrin peptides are one of the most commonly used AMPs in pig feeds. More recently, it was shown in a murine model of intestinal inflammation that treatment with porcine lactoferrinderived peptide LFP-20 was effective in the prevention of histological damage, the inflammatory response and the disruption of tight junction structure induced by LPS in the intestine [140]. Colicins, a class of bacteriocins produced by $E$. coli and closely related species, have been shown to inhibit the activities of ETEC: F4 and F18 strains in vitro and in vivo, and improve the growth performance, reduce the incidence of PWD and the expression of the IL- $1 \beta$ and TNF- $\beta$ genes in ileal tissues of pigs [141]. On the other hand, resistance to AMPs has been observed in vitro in GNB such as E. coli [142]. Thus, the use of AMPs in pig farms needs careful and controlled implementation to limit possible resistance development and cocktails of AMPs might be useful to mitigate selection for resistance [88].

Specific egg yolk antibodies: The chicken egg yolk is a source of large quantities of relatively inexpensive IgY antibodies [2]. Several studies reported that specific chicken antibodies provide protection against ETEC infections in pigs [111]. Despite the effectiveness of this practice, we have not found in the recent literature (last 5 years) any studies evaluating the use of specific egg yolk antibodies in PWD control. This is probably the consequence of the non-profitability in pig production of this practice, or the lack of protection against ETEC challenge or PWD occurrence, possibly because the antibodies contained in the eggs are not specific against the infected ETEC strains present on the farm [143].

Bacteriophages are highly species-specific viruses that can infect and kill bacteria. They have been widely evaluated in clinical trials to treat bacterial infections in pigs as an alternative to antibiotics use [144]. Recently, it was reported that dietary supplementation with 
bacteriophages for the treatment of PWD caused by an ETEC: F4 strain in an experimental model, was effective in reducing rectal temperature, faecal consistency score, E. coli adhesion score in the ileum and caecum, and villous height/crypt depth ratio $(\mathrm{VH} / \mathrm{CD})$ in the duodenum and jejunum [145]. However, there are several disadvantages associated with the use of phage therapy in swine. Phages have a narrow spectrum of activity directed against a limited number of bacteria and the possible development of bacterial resistance against phages has to be considered [144]. To overcome the narrow spectrum of activity, some recent studies have reported beneficial effects of a bacteriophage cocktail used in the feed for weanling pigs. This combination resulted in enhanced growth performance and gut health of pigs, although the combination of phages with probiotics did not show any additional effect [109]. Some authors have considered that the development of phage-resistant bacteria could be positive for the host [146]. In fact, resistance to phages can reduce the fitness of the bacteria and could thereby impair their competitive capacity and consequently their ability to colonize the intestinal mucosa of the host [146].

Others: Several studies have documented a significant improvement of weight gain, and feed conversion, as well as the reduction of the incidence, severity and duration of diarrhea in weaned pigs fed diets supplemented with substances such as: exogenous enzymes [147], milk products [148], clay minerals [149], and medicinal plants [150]. Although many peer-reviewed studies discussing these substances are available in the scientific literature, most of the clinical studies were performed in experimental conditions. More research is needed to evaluate the potential effectiveness of these substances under field conditions for the control of PWD in pigs.

\section{Results of comparative studies}

Several studies have been carried out in experimental conditions to assess the effectiveness of alternatives to colistin for the control of PWD in pigs (Table 4). Here, we give an overview of studies published in 2015 or 2016.

Several recent experimental studies have now shown that some alternatives (Table 4) resulted in similar or superior clinical outcomes compared to colistin for improving growth performance and intestinal integrity and in reducing of incidence of diarrhea in weaned pigs. In fact, no difference was observed in growth performance of weaned pigs supplemented with hop $\beta$-acids $(120,240$, or $360 \mathrm{mg} / \mathrm{kg})$ or colistin $(40 \mathrm{mg} / \mathrm{kg})$ during a trial period of 35 days [151]. Moreover, the supplementation of weaned pigs with two Macrocephala flavored powder $(3000 \mathrm{mg} / \mathrm{kg})$ increased significantly villus height in the duodenum and jejunum compared to that observed in colistin $(300 \mathrm{mg} / \mathrm{kg})$ supplemented pigs [152]. However, these studies (Table 4), were conducted in experimental conditions and in most cases in healthy weaned pigs. Thus, further research is needed to demonstrate the stability and the efficacy of such alternatives (probiotics, AMPs, medicinal plants) in field conditions as well as the safety of these substances in animals and for consumers. Also, work is needed to optimize the doses of these substances to incorporate in the feed to ensure their effectiveness in PWD control. The financial cost and the ease of administration of such alternatives are the other important criteria that should be taken into consideration in pig production.

\section{Limits and perspectives}

A long and growing list of compounds have been tested for their ability to replace colistin or other antibiotics for the control of PWD in pigs. However, it is difficult to identify a single "ideal" solution for PWD management. Also, as was discussed above, PWD is a multifactorial disease and the exact overall etiology has not yet been fully elucidated, making it difficult to choose suitable alternatives. Moreover, the most of these alternatives produce inconsistent results regarding their effectiveness in field conditions [107]. Oral administration of specificantibody-containing egg yolk, or SDP to weaned piglets showed in some cases no protection against ETEC strains or PWD outcomes, likely because the contained antibodies were not specific against the infecting ETEC strains present on the farm [2]. The composition of plant extracts, organic acids and probiotics is complex and knowledge regarding their mechanisms of action is poor, resulting in variable results and safety risks [87]. Synergy mechanisms of probiotics and prebiotics are not very well known nor well studied [133]. Although AMPs and bacteriophages helped in the treatment of PWD, the bacterial resistance risk, the high cost and the narrow antibacterial spectrum of these alternatives reduce their practical use on farms [88]. Vaccination is one of the most promising strategies for the control of PWD in pigs both in terms of preventive ability and cost-effectiveness [97]. The control of production parameters (temperature, ventilation, density, sanitation, biosafety, improvement of feed quality) are crucial factors for the control of PWD and the reduction of the use of antimicrobials during the post-weaning period [28]. However, the improvement of farm conditions and management requires investment and awareness of pig farmers. Furthermore, the use of regular diagnostic testing is crucial to ensure an appropriate choice of the antimicrobial and to monitor its effectiveness on farms. Thus, efforts to improve microbiological laboratory detection methods are of paramount importance to help the veterinarian to act rapidly at an early stage of the disease [153]. 
Table 4 Effects of colistin compared to alternative measures for control of post weaning diarrhoea (PWD) in pigs

\begin{tabular}{|c|c|c|c|c|c|c|}
\hline Trials & ADG (g/day) & Ileum villus height ( $\mu \mathrm{m})$ & Ileum crypt depth $(\mu \mathrm{m})$ & E. coli $(\log 10 \mathrm{CFU} / \mathrm{g})$ & Diarrhea & References \\
\hline Study 1: HP & $\mathrm{d} 0-35$ & d35 & $d 35$ & & $\mathrm{~d} 0-21^{\mathrm{c}}$ & [151] \\
\hline Hop $\beta$-acids ${ }^{\mathrm{e}}(360$ mg/kg) & $441^{\mathrm{a}}$ & 337 & 214 & NA & 1.51 & \\
\hline Colistin sulfate (40 mg/kg) & $425^{\mathrm{a}}$ & 366 & 230 & NA & 1.51 & \\
\hline Control & $387^{b}$ & 349 & 219 & NA & 1.72 & \\
\hline Study 2: HP & $d 21$ & $d 21$ & $d 21$ & $\mathrm{~d} 21$ & & [152] \\
\hline $\begin{array}{l}\text { Two Macrocephala flavored } \\
\text { powder (3000 mg/kg) }\end{array}$ & NA & 121 & 66.30 & $7.93^{\mathrm{a}}$ & NA & \\
\hline Colistin sulfate (300 mg/kg) & NA & 107 & 57.63 & $6.48^{\mathrm{a}}$ & NA & \\
\hline Control & NA & 120.49 & 64.75 & 6.63 & NA & \\
\hline Study 3: HP & $\mathrm{d} 1-21$ & $d 21$ & $d 21$ & Ileum d $21^{f}$ & $\mathrm{~d} 1-7^{\mathrm{c}}$ & [79] \\
\hline $\begin{array}{l}\text { Recombinant plectasin (Ple) } \\
(60 \mathrm{mg} / \mathrm{kg})\end{array}$ & $311.43^{\mathrm{a}}$ & 227.69 & 95.53 & 6.61 & 10.48 & \\
\hline Colistin sulfate (60 mg/kg) & $333.57^{\mathrm{a}}$ & 195.57 & 88.48 & 5.86 & 8.57 & \\
\hline Control & $193.10^{b}$ & 160.45 & 105.82 & 6.29 & 36.19 & \\
\hline Study 4: HP & $\mathrm{d} 0-14$ & & & & $\mathrm{~d} 0-14$ & [81] \\
\hline $\begin{array}{l}\text { Medium-chain triglyceride } \\
\text { (MCT) (3000 mg/kg) }\end{array}$ & 141.2 & NA & NA & NA & 0.91 & \\
\hline Colistin sulfate (40 mg/kg) & 142.2 & NA & NA & NA & 0.91 & \\
\hline Control & 130.7 & NA & NA & NA & 1.01 & \\
\hline Study 5: HP & $d 28-56$ & $d 42$ & $d 42$ & & $d 28-56^{d}$ & [157] \\
\hline $\begin{array}{l}\text { Freshwater microalgae Chlo- } \\
\text { rella vulgaris (1000 mg/kg) }\end{array}$ & 395 & 435 & 278 & NA & $24^{b}$ & \\
\hline Colistin sulfate (20 mg/kg) & 400 & 440 & 283 & NA & $34^{\mathrm{a}}$ & \\
\hline Control & 393 & 415 & 299 & NA & $36^{\mathrm{a}}$ & \\
\hline Study 6: CP & & d1 post challenge $e^{e}$ & d1 post challenge $e^{e}$ & & & [158] \\
\hline Live yeast $\left(5 \times 10^{10} \mathrm{CFU} / \mathrm{kg}\right)$ & NA & 322 & 246 & NA & NA & \\
\hline Colistin sulfate (1000 mg/kg) & NA & 334 & 236 & NA & NA & \\
\hline Control & NA & 294 & 199 & NA & NA & \\
\hline
\end{tabular}

Live yeast: Saccharomyces cerevisiae

$H P$ healthy pigs, $C P$ challenged pigs, NA not available

a,b Values within a row with different superscripts differ significantly at $P<0.05$

c Diarrhea occurrence was calculated as the proportion of days in which pigs showed clinical signs of diarrhea

d Number of pig days with diarrhoea score $\geq 2$

e Jejunum

${ }^{\mathrm{f}} \log ($ copies/g)

For the management of PWD in different stages of its evolution, we propose a comprehensive approach that involves producers, the nutrition industry, veterinarians, the diagnostic laboratory, and researchers (Fig. 3). The absence of a well-identified etiology of PWD and of an effective alternative to antimicrobials requires a close collaboration between the different stakeholders to reduce antibiotic resistance and economic losses caused by this disease in swine.

\section{Conclusions}

Despite the progress that has been observed in modern pig farms during the last decade to prevent infectious diseases and improve global animal health, PWD remains a problem that causes significant economic losses in pig production. Antibiotics have contributed significantly to mitigate the economic losses caused by infectious diseases and particularly PWD in swine. However, increasing bacterial resistance leading to therapeutic failures on farms as well as the greater vigilance of consumers regarding antimicrobial residues, have resulted in more intensive research and a large number of clinical trials for the development of alternatives to antimicrobials. Thus, several alternatives have been developed, some of which have been commercialized for the management of PWD in pigs. However, the effectiveness of these news therapies has been variable from one farm to another due to the management of livestock and farm conditions. Although 


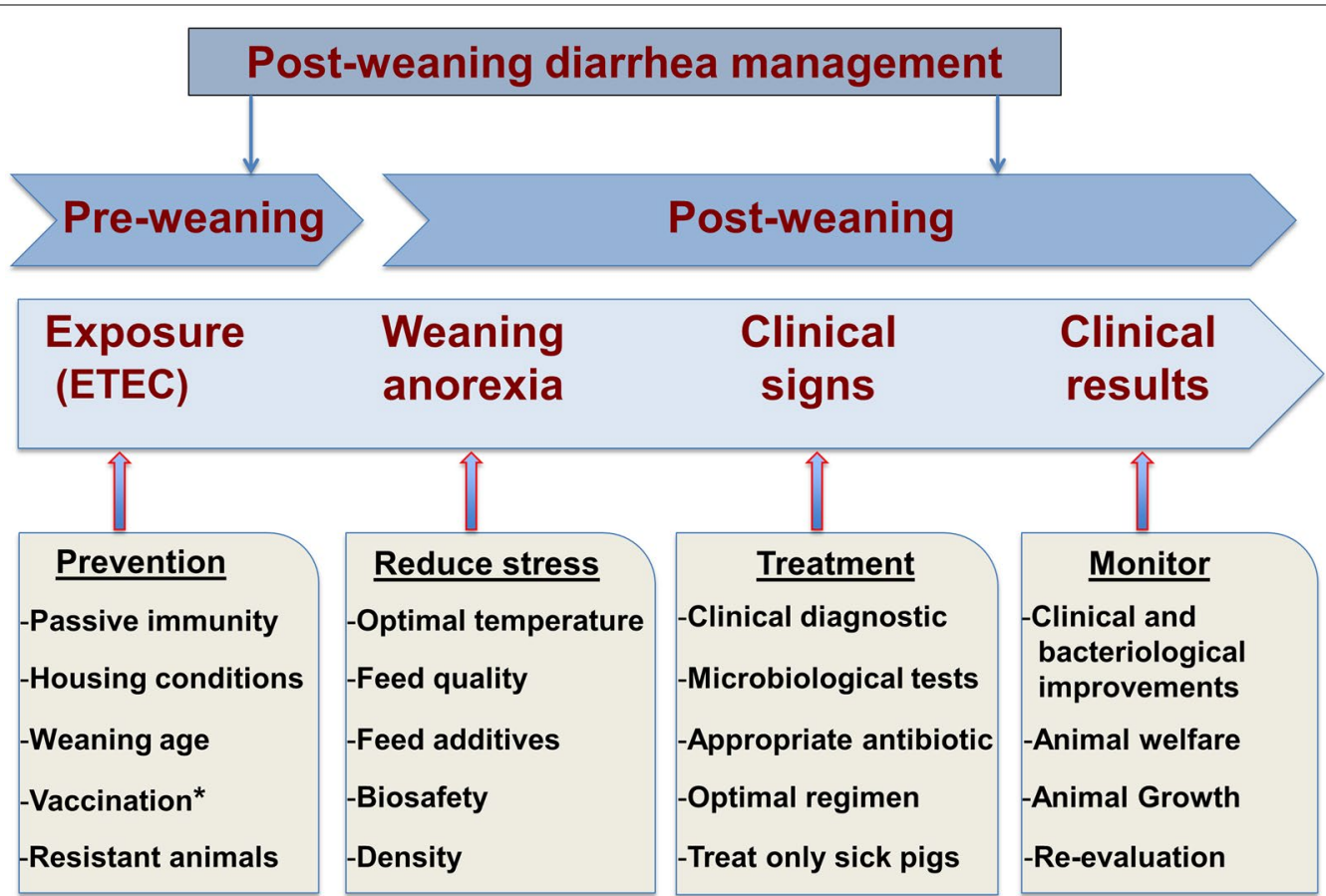

Fig. 3 Illustrative interventions for the management of post-weaning diarrhea in pig farms. Asterisk Vaccination just prior to or at weaning (Inspired from [159])

some alternatives have shown comparable efficacy to antimicrobials or colistin in the control of PWD, there is still a considerable gap between these alternatives and antibiotics concerning their effectiveness in PWD control. Control of housing conditions and vaccination are the most promising strategies for the prevention of PWD in pigs and for reducing of the overall use of antimicrobials on farms. However, the establishment and the effectiveness of these strategies depend on the involvement of all stakeholders in pig farming. Judicious use of antimicrobials in pigs and continued development of alternatives to antimicrobials and colistin remains a priority to ensure a long-term sustainable development in pigs.

\section{Authors' contributions}

MR was the main contributor to the conception, design, and writing of the paper; JMF contributed to the design and writing of the paper; FB contributed to the design and revision of the paper; $\mathrm{AL}$ contributed to the design and drafting of the paper. All authors read and approved the final manuscript.

\section{Author details}

${ }^{1}$ Department of Pathology and Microbiology, Faculty of Veterinary Medicine, University of Montreal, 3200 Sicotte Street, Saint-Hyacinthe, QC J2S 2M2,

Canada. ${ }^{2}$ Department of Veterinary Biomedicine, Faculty of Veterinary Medicine, University of Montreal, 3200 Sicotte Street, Saint-Hyacinthe, QC J2S 2M2, Canada.

\section{Acknowledgements}

This work was supported by the Natural Sciences and Engineering Research Council of Canada (NSERC) (412247-10) and financial partners in the Industrial Research Chair in Meat Safety. The authors thank Ms. Dominique Croteau for the artwork.
Competing interests

The authors declare that they have no competing interests.

\section{Publisher's Note}

Springer Nature remains neutral with regard to jurisdictional claims in published maps and institutional affiliations.

Received: 3 December 2016 Accepted: 11 May 2017

Published online: 19 May 2017

References

1. Amezcua R, Friendship RM, Dewey CE, Gyles C, Fairbrother JM. Presentation of postweaning Escherichia coli diarrhea in southern Ontario, prevalence of hemolytic E. coli serogroups involved, and their antimicrobial resistance patterns. Can J Vet Res. 2002;66:73-8.

2. Fairbrother JM, Nadeau E, Gyles CL. Escherichia coli in postweaning diarrhea in pigs: an update on bacterial types, pathogenesis, and prevention strategies. Anim Health Res Rev. 2005;6:17-39.

3. McCracken BA, Spurlock ME, Roos MA, Zuckermann FA, Gaskins HR. Weaning anorexia may contribute to local inflammation in the piglet small intestine. J Nutr. 1999:129:613-9.

4. Lallès J-P, Boudry G, Favier C, Le Floc'h N, Luron I, Montagne L, et al. Gut function and dysfunction in young pigs: physiology. Anim Res. 2004;53:301-16.

5. Lallès J-P, Bosi P, Smidt H, Stokes CR. Weaning - a challenge to gut physiologists. Livest Sci. 2007;108:82-93.

6. Luppi A, Gibellini AM, Gin T, Vangroenweghe F, Vandenbroucke V, Bauerfeind $\mathrm{R}$, et al. Prevalence of virulence factors in enterotoxigenic Escherichia coli isolated from pigs with post-weaning diarrhoea in Europe. Porcine Health Manag. 2016;2:1-6.

7. Nagy B, Fekete PZ. Enterotoxigenic Escherichia coli in veterinary medicine. Int J Med Microbiol. 2005:295:443-54. 
8. Delisle B, Calinescu C, Mateescu MA, Fairbrother JM, Nadeau E. Oral immunization with F4 fimbriae and $\mathrm{CpG}$ formulated with carboxymethyl starch enhances F4-specific mucosal immune response and modulates Th1 and Th2 cytokines in weaned pigs. J Pharm Pharm Sci. 2012;15:642-56

9. Tambadou F, Caradec T, Gagez A-L, Bonnet A, Sopéna V, Bridiau N, et al. Characterization of the colistin (polymyxin E1 and E2) biosynthetic gene cluster. Arch Microbiol. 2015;197:521-32.

10. Kempf I, Fleury MA, Drider D, Bruneau M, Sanders P, Chauvin C, et al. What do we know about resistance to colistin in Enterobacteriaceae in avian and pig production in Europe? Int J Antimicrob Agents. 2013;42:379-83.

11. Walkty A, DeCorby M, Nichol K, Karlowsky JA, Hoban DJ, Zhanel GG. In vitro activity of colistin (polymyxin E) against 3,480 isolates of gram-negative bacilli obtained from patients in Canadian hospitals in the CANWARD study, 2007-2008. Antimicrob Agents Chemother. 2009;53:4924-6.

12. Michalopoulos AS, Karatza DC, Gregorakos L. Pharmacokinetic evaluation of colistin sodium. Expert Opin Drug Metab Toxicol. 2011:7:245-55.

13. Boyen F, Vangroenweghe F, Butaye P, De Graef E, Castryck F, Heylen P, et al. Disk prediffusion is a reliable method for testing colistin susceptibility in porcine E. coli strains. Vet Microbiol. 2010;144:359-62.

14. Morales AS, Fragoso de Araujo J, De Moura Gomes VT, Reis Costa AT, Dos Prazeres Rodrigues D, et al. Colistin resistance in Escherichia coli and Salmonella enterica strains isolated from swine in Brazil. Sci World J. 2012;2012:1-4.

15. Harada K, Asai T, Kojima A, Oda C, Ishihara K, Takahashi T. Antimicrobial susceptibility of pathogenic Escherichia coli isolated from sick cattle and pigs in Japan. J Vet Med Sci. 2005;67:999-1003.

16. Schwarz S, Johnson AP. Transferable resistance to colistin: a new but old threat. J Antimicrob Chemother. 2016;71:2066-70.

17. Liu YY, Wang Y, Walsh TR, Yi LX, Zhang R, Spencer J, et al. Emergence of plasmid-mediated colistin resistance mechanism MCR-1 in animals and human beings in China: a microbiological and molecular biological study. Lancet Infect Dis. 2016;16:161-8.

18. Rhouma M, Beaudry F, Letellier A. Resistance to colistin: what is the fate for this antibiotic in pig production? Int J Antimicrob Agents. 2016:48:119-26.

19. Nordmann P, Poirel L. Plasmid-mediated colistin resistance: an additional antibiotic resistance menace. Clin Microbiol Infect. 2016;22:398-400.

20. European Medicines Agency. European medicines agency to review guidance on colistin use in animals. Vet Rec. 2016:178:55.

21. Haenni M, Poirel L, Kieffer N, Châtre P, Saras E, Métayer V, et al. Cooccurrence of extended spectrum $\beta$ lactamase and MCR-1 encoding genes on plasmids. Lancet Infect Dis. 2016;16:281-2.

22. Du H, Chen L, Tang Y-W, Kreiswirth BN. Carbapenem-resistant and colistin-resistant Escherichia coli co-producing NDM-9 and MCR-1. Lancet Infect Dis. 2016;16:287-8.

23. Rhouma M, Letellier A. Extended-spectrum beta-lactamases, carbapenemases and the $\mathrm{mcr}-1$ gene: is there a historical link? Int J Antimicrob Agents. 2017:49:269-71.

24. Xu G, An W, Wang H, Zhang X. Prevalence and characteristics of extended-spectrum $\beta$-lactamase genes in Escherichia coli isolated from piglets with post-weaning diarrhea in Heilongjiang province, China. Front Microbiol. 2015:6:1103.

25. Rhouma M, Beaudry F, Theriault W, Letellier A. Colistin in pig production: chemistry, mechanism of antibacterial action, microbial resistance emergence, and one health perspectives. Front Microbiol. 2016;7:1-22.

26. Jensen GM, Frydendahl K, Svendsen O, Jorgensen CB, Cirera S, Fredholm M, et al. Experimental infection with Escherichia coli O149:F4ac in weaned piglets. Vet Microbiol. 2006;115:243-9.

27. Hong T, Linh N, Ogle B, Lindberg J. Survey on the prevalence of diarrhoea in pre-weaning piglets and on feeding systems as contributing risk factors in smallholdings in Central Vietnam. Trop Anim Health Prod. 2006;38:397-405.

28. Rhouma M, Beaudry F, Theriault W, Bergeron N, Beauchamp G, LaurentLewandowski S, et al. In vivo therapeutic efficacy and pharmacokinetics of colistin sulfate in an experimental model of enterotoxigenic Escherichia coli infection in weaned pigs. Vet Res. 2016;47:58.
29. Muns R, Nuntapaitoon M, Tummaruk P. Non-infectious causes of preweaning mortality in piglets. Livest Sci. 2016;184:46-57.

30. Madec F, Bridoux N, Bounaix S, Jestin A. Measurement of digestive disorders in the piglet at weaning and related risk factors. Prev Vet Med. 1998;35:53-72.

31. Heo J, Opapeju F, Pluske J, Kim J, Hampson D, Nyachoti C. Gastrointestinal health and function in weaned pigs: a review of feeding strategies to control post-weaning diarrhoea without using in-feed antimicrobial compounds. J Anim Physiol Anim Nutr. 2013;97:207-37.

32. Porter $P$, Noakes DE, Allen WD. Secretory IgA and antibodies to Escherichia coli in porcine colostrum and milk and their significance in the alimentary tract of the young pig. Immunology. 1970;18:245-57.

33. Main R, Dritz S, Tokach M, Goodband R, Nelssen J. Increasing weaning age improves pig performance in a multisite production system. J Anim Sci. 2004;82:1499-507.

34. Baxter E, Rutherford K, D'Eath R, Arnott G, Turner S, Sandøe P, et al. The welfare implications of large litter size in the domestic pig II: management factors. Anim Welf. 2013;22:219-38.

35. McLamb BL, Gibson AJ, Overman EL, Stahl C, Moeser AJ. Early weaning stress in pigs impairs innate mucosal immune responses to enterotoxigenic E. coli challenge and exacerbates intestinal injury and clinical disease. PLOS ONE. 2013:8:e59838. doi:10.1371/journal. pone.0059838

36. Le Dividich J, Seve B. Effects of underfeeding during the weaning period on growth, metabolism, and hormonal adjustments in the piglet. Domest Anim Endocrinol. 2000;19:63-74.

37. Campbell JM, Crenshaw JD, Polo J. The biological stress of early weaned piglets. J Anim Sci Biotechnol. 2013;4:19.

38. Laine TM, Lyytikäinen T, Yliaho M, Anttila M. Risk factors for post-weaning diarrhoea on piglet producing farms in Finland. Acta Vet Scand. 2008:50:1.

39. Le Dividich J, Herpin P. Effects of climatic conditions on the performance, metabolism and health status of weaned piglets: a review. Livest Prod Sci. 1994;38:79-90.

40. Fairbrother JM, Gyles CL. Colibacillosis. In: Zimmerman JJ, Dunne HW, editors. Diseases of swine. 10th ed. Chichester: Wiley-Blackwell; 2012. p. 723-49.

41. Wathes C, Whittemore C. Environmental management of pigs. In: Whittemore CT, Kyriazakis I, editors. Whittemore's science and practice of pig production. 3rd ed. Oxford: Blackwell Publishing; 2006. p. 533-92.

42. Breuer K, Sutcliffe MEM, Mercer JT, Rance KA, Beattie VE, Sneddon IA, et al. The effect of breed on the development of adverse social behavours in pigs. Appl Anim Behav Sci. 2003:84:59-74.

43. Amezcua R, Friendship R, Dewey C, Gyles C. A case-control study investigating risk factors associated with postweaning Escherichia coli diarrhea in southern Ontario. J Swine Health Prod. 2002;10:245-9.

44. Skirrow SZ, Buddle JR, Mercy AR, Madec F, Nicholls RR. Epidemiological studies of pig diseases: 2. Post-weaning diarrhoea and performance in Western Australian pigs. Aust Vet J. 1997;75:282-8.

45. Coutellier L, Arnould C, Boissy A, Orgeur P, Prunier A, Veissier l, et al. Pig's responses to repeated social regrouping and relocation during the growing-finishing period. Appl Anim Behav Sci. 2007;105:102-14.

46. Soraci AL, Amanto F, Tapia MO, De la Torre E, Toutain PL. Exposure variability of fosfomycin administered to pigs in food or water: impact of social rank. Res Vet Sci. 2014;96:153-9.

47. Boyd RD, Castro GC, Cabrera RA. Nutrition and management of the sow to maximize lifetime productivity. Adv Pork Product. 2002;13:1-12.

48. Katsuda K, Kohmoto M, Kawashima K, Tsunemitsu H. Frequency of enteropathogen detection in suckling and weaned pigs with diarrhea in Japan. J Vet Diagn Invest. 2006;18:350-4.

49. Nakamine M, Kono Y, Abe S, Hoshino C, Shirai J, Ezaki T. Dual infection with enterotoxigenic Escherichia coli and porcine reproductive and respiratory syndrome virus observed in weaning pigs that died suddenly. J Vet Med Sci. 1998;60:555-61.

50. Schroyen M, Stinckens A, Verhelst R, Niewold T, Buys N. The search for the gene mutations underlying enterotoxigenic Escherichia coli F4ab/ac susceptibility in pigs: a review. Vet Res. 2012:43:70.

51. Xia P, Zou Y, Wang Y, Song Y, Liu W, Francis DH, et al. Receptor for the F4 fimbriae of enterotoxigenic Escherichia coli (ETEC). Appl Microbiol Biotechnol. 2015;99:4953-9. 
52. Byun J-W, Jung BY, Kim H-Y, Fairbrother JM, Lee M-H, Lee W-K. Real-time PCR for differentiation of F18 variants among enterotoxigenic and shiga toxin-producing Escherichia coli from piglets with diarrhoea and oedema disease. Vet J. 2013;198:538-40.

53. Bertschinger $\mathrm{H}$, Nief $\mathrm{V}$, Tschäpe $\mathrm{H}$. Active oral immunization of suckling piglets to prevent colonization after weaning by enterotoxigenic Escherichia coli with fimbriae F18. Vet Microbiol. 2000;71:255-67.

54. Moredo FA, Pineyro PE, Marquez GC, Sanz M, Colello R, Etcheverria A, et al. Enterotoxigenic Escherichia coli subclinical infection in pigs: bacteriological and genotypic characterization and antimicrobial resistance profiles. Foodborne Pathog Dis. 2015;12:704-11.

55. Ravi M, Ngeleka M, Kim SH, Gyles C, Berthiaume F, Mourez M, et al. Contribution of AIDA-I to the pathogenicity of a porcine diarrheagenic Escherichia coli and to intestinal colonization through biofilm formation in pigs. Vet Microbiol. 2007;120:308-19.

56. Noamani BN, Fairbrother JM, Gyles CL. Virulence genes of O149 enterotoxigenic Escherichia coli from outbreaks of postweaning diarrhea in pigs. Vet Microbiol. 2003;97:87-101.

57. Gyles CL, Fairbrother JM. Escherichia coli. In: Gyles CL, Prescott JF, Songer $\mathrm{JG}$, Thoen CO, editors. Pathogenesis of bacterial infections in animals. 4th ed. Oxford: Blackwell Publishing; 2010. p. 267-308.

58. Rhouma M, Fairbrother JM, Theriault W, Beaudry F, Bergeron N, LaurentLewandowski S, et al. The fecal presence of enterotoxin and F4 genes as an indicator of efficacy of treatment with colistin sulfate in pigs. BMC Microbiol. 2017;17:6.

59. Zhang W, Berberov EM, Freeling J, He D, Moxley RA, Francis DH. Significance of heat-stable and heat-labile enterotoxins in porcine colibacillosis in an additive model for pathogenicity studies. Infect Immun. 2006;74:3107-14

60. Roubos-van den Hil PJ, Litjens R, Oudshoorn AK, Resink JW, Smits CH. New perspectives to theenterotoxigenic E. coli F4 porcine infection model: susceptibility genotypes in relation to performance, diarrhoea and bacterial shedding. Vet Microbiol. 2016; doi:10.1016/j.vetmic.2016.09.008.

61. Dubreuil JD, Isaacson RE, Schifferli DM. Animal enterotoxigenic Escherichia coli. EcoSal Plus. 2016;7. doi:10.1128/ecosalplus.ESP-0006-2016.

62. Nagy B, Fekete PZ. Enterotoxigenic Escherichia coli (ETEC) in farm animals. Vet Res. 1999;30:259-84

63. Madec F, Bridoux N, Bounaix S, Cariolet R, Duval-Iflah Y, Hampson DJ, et al. Experimental models of porcine post-weaning colibacillosis and their relationship to post-weaning diarrhoea and digestive disorders as encountered in the field. Vet Microbiol. 2000;72:295-310.

64. Faubert C, Drolet R. Hemorrhagic gastroenteritis caused by Escherichia coli in piglets: clinical, pathological and microbiological findings. Can Vet J. 1992;33:251-6.

65. Berberov EM, Zhou Y, Francis DH, Scott MA, Kachman SD, Moxley RA. Relative importance of heat-labile enterotoxin in the causation of severe diarrheal disease in the gnotobiotic piglet model by a strain of enterotoxigenic Escherichia coli that produces multiple enterotoxins. Infect Immun. 2004;72:3914-24

66. Moxley RA, Berberov EM, Francis DH, Xing J, Moayeri M, Welch RA, et al. Pathogenicity of an enterotoxigenic Escherichia coli hemolysin (hlyA) mutant in gnotobiotic piglets. Infect Immun. 1998;66:5031-5.

67. Gao Y, Han F, Huang X, Rong Y, Yi H, Wang Y. Changes in gut microbial populations, intestinal morphology, expression of tight junction proteins, and cytokine production between two pig breeds after challenge with K88: a comparative study. J Anim Sci. 2013;91:5614-25.

68. Maynard C, Fairbrother JM, Bekal S, Sanschagrin F, Levesque RC, Brousseau R, et al. Antimicrobial resistance genes in enterotoxigenic Escherichia coli O149:K91 isolates obtained over a 23-year period from pigs. Antimicrob Agents Chemother. 2003;47:3214-21.

69. Katsunuma $Y$, Hanazumi M, Fujisaki $\mathrm{H}$, Minato $\mathrm{H}$, Hashimoto $\mathrm{Y}$, Yonemochi C. Associations between the use of antimicrobial agents for growth promotion and the occurrence of antimicrobial-resistant Escherichia coli and enterococci in the feces of livestock and livestock farmers in Japan. $J$ Gen Appl Mmicrobiol. 2007;53:273-9.

70. Catry B, Cavaleri M, Baptiste K, Grave K, Grein K, Holm A, et al. Use of colistin-containing products within the European Union and European Economic Area (EU/EEA): development of resistance in animals and possible impact on human and animal health. Int J Antimicrob Agents. 2015:46:297-306.
71. Rhouma M, Beaudry F, Thériault W, Bergeron N, Laurent-Lewandowski S, Fairbrother JM, et al. Gastric stability and oral bioavailability of colistin sulfate in pigs challenged or not with Escherichia coli 0149:F4 (K88). Res Vet Sci. 2015;102:173-81.

72. Jensen VF, Emborg HD, Aarestrup FM. Indications and patterns of therapeutic use of antimicrobial agents in the Danish pig production from 2002 to 2008. J Vet Pharmacol Ther. 2012;35:33-46.

73. Timmerman T, Dewulf J, Catry B, Feyen B, Opsomer G, De Kruif A, et al. Quantification and evaluation of antimicrobial drug use in group treatments for fattening pigs in Belgium. Prev Vet Med. 2006;74:251-63.

74. Callens B, Persoons D, Maes D, Laanen M, Postma M, Boyen F, et al. Prophylactic and metaphylactic antimicrobial use in Belgian fattening pig herds. Prev Vet Med. 2012;106:53-62.

75. Van Rennings L, Von Munchhausen C, Ottilie H, Hartmann M, Merle $\mathrm{R}$, Honscha W, et al. Cross-sectional study on antibiotic usage in pigs in Germany. PLoS ONE. 2015;10:e0119114. doi:10.1371/journal. pone.0119114.

76. Kim DP, Saegerman C, Douny C, Dinh TV, Xuan BH, Vu BD, et al. First survey on the use of antibiotics in pig and poultry production in the Red River Delta region of Vietnam. Food Pub Health. 2013;3:247-56.

77. Torrallardona D, Conde R, Badiola I, Polo J. Evaluation of spray dried animal plasma and calcium formate as alternatives to colistin in piglets experimentally infected with Escherichia coli K99. Livest Sci. 2007;108:303-6.

78. Tang Z, Deng H, Zhang X, Zen Y, Xiao D, Sun W, et al. Effects of orally administering the antimicrobial peptide buforin II on small intestinal mucosal membrane integrity, the expression of tight junction proteins and protective factors in weaned piglets challenged by enterotoxigenic Escherichia coli. Anim Feed Sci Technol. 2013;186:177-85.

79. Wan J, Li Y, Chen D, Yu B, Chen G, Zheng P, et al. Recombinant plectasin elicits similar improvements in the performance and intestinal mucosa growth and activity in weaned pigs as an antibiotic. Anim Feed Sci Technol. 2016;211:216-26.

80. Fleury M, Jouy E, Eono F, Cariolet R, Couet W, Gobin P, et al. Impact of two different colistin dosing strategies on healthy piglet fecal microbiota. Res Vet Sci. 2016;107:152-60.

81. Yen HC, Lai WK, Lin CS, Chiang SH. Medium-chain triglyceride as an alternative of in-feed colistin sulfate to improve growth performance and intestinal microbial environment in newly weaned pigs. Anim Sci J. 2015:86:99-104.

82. Graham JP, Boland JJ, Silbergeld E. Growth promoting antibiotics in food animal production: an economic analysis. Public Health Rep. 2007;122:79-87.

83. Malhotra-Kumar S, Xavier BB, Das AJ, Lammens C, Hoang HTT, Pham NT, et al. Colistin-resistant Escherichia coli harbouring mcr-1 isolated from food animals in Hanoi, Vietnam. Lancet Infect Dis. 2016;16:286-7.

84. Falgenhauer L, Waezsada S-E, Yao Y, Imirzalioglu C, Käsbohrer A, Roesler $\mathrm{U}$, et al. Colistin resistance gene $\mathrm{mcr}-1$ in extended-spectrum $\beta$-lactamase-producing and carbapenemase-producing Gram-negative bacteria in Germany. Lancet Infect Dis. 2016;16:282-3.

85. Nguyen NT, Nguyen HM, Nguyen CV, Nguyen TV, Nguyen MT, Thai $\mathrm{HQ}$, et al. The use of colistin and other critical antimicrobials on pig and chicken farms in southern Vietnam and their association with resistance in commensal Escherichia coli. Appl Environ Microbiol. 2016;82:3727-35.

86. Anjum MF, Duggett NA, AbuOun M, Randall L, Nunez-Garcia J, Ellis RJ, et al. Colistin resistance in Salmonella and Escherichia coli isolates from a pig farm in Great Britain. J Antimicrob Chemother. 2016;8(23):6-13.

87. Cheng $G$, Hao H, Xie S, Wang X, Dai M, Huang L, et al. Antibiotic alternatives: the substitution of antibiotics in animal husbandry? Front Microbiol. 2014:5:217.

88. Allen HK, Trachsel J, Looft T, Casey TA. Finding alternatives to antibiotics. Ann NY Acad Sci. 2014;1323:91-100.

89. Wang S, Zeng X, Yang Q, Qiao S. Antimicrobial peptides as potential alternatives to antibiotics in food animal industry. Int J Mol Sci. 2016;17:1-12.

90. Caly DL, D'Inca R, Auclair E, Drider D. Alternatives to antibiotics to prevent necrotic enteritis in broiler chickens: a microbiologist's perspective. Front Microbiol. 2015;6:1336. 
91. Gardner IA, Willeberg P, Mousing J. Empirical and theoretical evidence for herd size as a risk factor for swine diseases. Anim Health Res Rev. 2002;3:43-55.

92. Dreau D, Lalles JP, Philouze-Rome V, Toullec R, Salmon H. Local and systemic immune responses to soybean protein ingestion in early-weaned pigs. J Anim Sci. 1994;72:2090-8

93. Salgado P, Freire JPB, Mourato M, Cabral F, Toullec R, Lallès JP. Comparative effects of different legume protein sources in weaned piglets: nutrient digestibility, intestinal morphology and digestive enzymes. Livest Prod Sci. 2002;74:191-202.

94. Visschers V, Backhans A, Collineau L, Iten D, Loesken S, Postma M, et al. Perceptions of antimicrobial usage, antimicrobial resistance and policy measures to reduce antimicrobial usage in convenient samples of Belgian, French, German, Swedish and Swiss pig farmers. Prev Vet Med. 2015:119:10-20.

95. Postma M, Stärk KD, Sjölund M, Backhans A, Beilage EG, Lösken S, et al. Alternatives to the use of antimicrobial agents in pig production: a multi-country expert-ranking of perceived effectiveness, feasibility and return on investment. Prev Vet Med. 2015;118:457-66.

96. Bak H, Rathkjen PH. Reduced use of antimicrobials after vaccination of pigs against porcine proliferative enteropathy in a Danish SPF herd. Acta Vet Scand. 2009:51:1.

97. Melkebeek V, Goddeeris BM, Cox E. ETEC vaccination in pigs. Vet Immunol Immunopathol. 2013;152:37-42.

98. Nadeau E, Fairbrother JM. Use of live bacteria for growth promotion in animals. In: Google Patents; 2011.

99. Tiels P, Verdonck F, Coddens A, Goddeeris B, Cox E. The excretion of $\mathrm{F} 18+E$. coli is reduced after oral immunisation of pigs with a FedF and F4 fimbriae conjugate. Vaccine. 2008;26:2154-63.

100. Takeyama N, Yuki Y, Tokuhara D, Oroku K, Mejima M, Kurokawa S, et al. Oral rice-based vaccine induces passive and active immunity against enterotoxigenic E. coli-mediated diarrhea in pigs. Vaccine. 2015;33:5204-11.

101. Zhang W, Sack DA. Current progress in developing subunit vaccines against enterotoxigenic Escherichia coli-associated diarrhea. Clin Vaccine Immunol. 2015;22:983-91.

102. Rasschaert K, Verdonck F, Goddeeris BM, Duchateau L, Cox E. Screening of pigs resistant to $\mathrm{F} 4$ enterotoxigenic Escherichia coli (ETEC) infection. Vet Microbiol. 2007;123:249-53.

103. Daudelin JF, Lessard M, Beaudoin F, Nadeau E, Bissonnette N, Boutin Y, et al. Administration of probiotics influences F4 (K88)-positive enterotoxigenic Escherichia coli attachment and intestinal cytokine expression in weaned pigs. Vet Res. 2011;42:69-80.

104. Edfors-Lilja I, Petersson H, Gahne B. Performance of pigs with or without the intestinal receptor for Escherichia coli K88. Anim Prod. 1986:42:381-7.

105. Zhou D, Zhu YH, Zhang W, Wang ML, Fan WY, Song D, et al. Oral administration of a select mixture of Bacillus probiotics generates Tr1 cells in weaned F4ab/acR - pigs challenged with an F4 + ETEC/NTEC/EPEC strain. Vet Res. 2015;46:95.

106. Pérez-Bosque A, Polo J, Torrallardona D. Spray dried plasma as an alternative to antibiotics in piglet feeds, mode of action and biosafety. Porc Health Manag. 2016;2:1-10.

107. Thacker PA. Alternatives to antibiotics as growth promoters for use in swine production: a review. J Anim Sci Biotechnol. 2013;4:35.

108. Suiryanrayna MV, Ramana JV. A review of the effects of dietary organic acids fed to swine. J Anim Sci Biotechnol. 2015;6:1-11.

109. Kim JS, Hosseindoust A, Lee SH, Choi YH, Kim MJ, Lee JH, et al. Bacteriophage cocktail and multistrain probiotics in the feed for weanling pigs: effects on intestine morphology and targeted intestinal coliforms and Clostridium. Animal. 2017;11:45-53.

110. Wittish LM, McElroy AP, Harper AF, Estienne MJ. Performance and physiology of pigs administered spray-dried plasma protein during the late suckling period and transported after weaning. J Anim Sci. 2014;92:4390-9.

111. Adewole DI, Kim IH, Nyachoti CM. Gut health of pigs: challenge models and response criteria with a critical analysis of the effectiveness of selected feed additives - a review. Asian Australas J Anim Sci. 2016:29:909-24
112. Zhu C, Lv H, Chen Z, Wang L, Wu X, Chen Z, et al. Dietary zinc oxide modulates antioxidant capacity, small intestine development, and jejunal gene expression in weaned piglets. Biol Trace Elem Res. 2016. doi:10.1007/s12011-016-0767-3.

113. Vahjen W, Pietruszynska D, Starke IC, Zentek J. High dietary zinc supplementation increases the occurrence of tetracycline and sulfonamide resistance genes in the intestine of weaned pigs. Gut Pathog. 2015;7:23.

114. Bednorz C, Oelgeschlager K, Kinnemann B, Hartmann S, Neumann K, Pieper $R$, et al. The broader context of antibiotic resistance: zinc feed supplementation of piglets increases the proportion of multi-resistant Escherichia coli in vivo. Int J Med Microbiol. 2013:303:396-403.

115. Holman DB, Chénier MR. Antimicrobial use in swine production and its effect on the swine gut microbiota and antimicrobial resistance. Can J Microbiol. 2015;61:785-98.

116. Yazdankhah S, Rudi K, Bernhoft A. Zinc and copper in animal feeddevelopment of resistance and co-resistance to antimicrobial agents in bacteria of animal origin. Microb Ecol Health Dis. 2014. doi:10.3402/mehd. v25.25862.

117. Bouwhuis MA, Sweeney T, Mukhopadhya A, Thornton K, McAlpine PO, O'Doherty JV. Zinc methionine and laminarin have growth-enhancing properties in newly weaned pigs influencing both intestinal health and diarrhoea occurrence. J Anim Physiol Anim Nutr (Berl). 2016. doi:10.1111/jpn.12647.

118. Hansen C, Riis A, Bresson S, Hojbjerg O, Jensen B. Feeding organic acids enhances the barrier function against pathogenic bacteria of the piglet stomach. Livest Sci. 2007;108:206-9.

119. Risley CR, Kornegay ET, Lindemann MD, Wood CM, Eigel WN. Effect of feeding organic acids on selected intestinal content measurements at varying times postweaning in pigs. J Anim Sci. 1992;70:196-206.

120. Ferrara F, Tedin L, Pieper R, Meyer W, Zentek J. Influence of mediumchain fatty acids and short-chain organic acids on jejunal morphology and intra-epithelial immune cells in weaned piglets. J Anim Physiol Anim Nutr (Berl). 2017:101:531-40.

121. Tsiloyiannis VK, Kyriakis SC, Vlemmas J, Sarris K. The effect of organic acids on the control of porcine post-weaning diarrhoea. Res Vet Sci. 2001;70:287-93.

122. Allen HK, Levine UY, Looft T, Bandrick M, Casey TA. Treatment, promotion, commotion: antibiotic alternatives in food-producing animals. Trends Microbiol. 2013;21:114-9.

123. Callaway TR, Edrington TS, Anderson RC, Harvey RB, Genovese KJ, Kennedy CN, et al. Probiotics, prebiotics and competitive exclusion for prophylaxis against bacterial disease. Anim Health Res Rev. 2008;9:217-25.

124. Slavin J. Fiber and prebiotics: mechanisms and health benefits. Nutrients. 2013:5:1417-35.

125. Liu P, Piao XS, Kim SW, Wang L, Shen YB, Lee HS, et al. Effects of chitooligosaccharide supplementation on the growth performance, nutrient digestibility, intestinal morphology, and fecal shedding of Escherichia coli and Lactobacillus in weaning pigs. J Anim Sci. 2008:86:2609-18.

126. Kiarie EG, Slominski BA, Krause DO, Nyachoti CM. Nonstarch polysaccharide hydrolysis products of soybean and canola meal protect against enterotoxigenic Escherichia coli in piglets. J Nutr. 2008; 138:502-8

127. Badia R, Zanello G, Chevaleyre C, Lizardo R, Meurens F, Martinez $P$, et al. Effect of Saccharomyces cerevisiae var. Boulardii and betagalactomannan oligosaccharide on porcine intestinal epithelial and dendritic cells challenged in vitro with Escherichia coli F4 (K88). Vet Res. 2012;43:4.

128. Zhang L, XU YQ, Liu HY, Lai T, Ma JL, Wang JF, et al. Evaluation of Lactobacillus rhamnosus GG using an Escherichia coli K88 model of piglet diarrhoea: effects on diarrhoea incidence, faecal microflora and immune responses. Vet Microbiol. 2010;141:142-8.

129. Lan R, Koo J, Kim I. Effects of Lactobacillus acidophilus supplementation on growth performance, nutrient digestibility, fecal microbial and noxious gas emission in weaning pigs. J Sci Food Agric. 2016;97:1310-5.

130. Yang GY, Zhu YH, Zhang W, Zhou D, Zhai CC, Wang JF. Influence of orally fed a select mixture of Bacillus probiotics on intestinal T-cell migration in weaned MUC4 resistant pigs following Escherichia coli challenge. Vet Res. 2016:47:71. 
131. Trckova M, Faldyna M, Alexa P, Sramkova Zajacova Z, Gopfert E, Kumprechtova D, et al. The effects of live yeast Saccharomyces cerevisiae on postweaning diarrhea, immune response, and growth performance in weaned piglets. J Anim Sci. 2014;92:767-74.

132. Vondruskova H, Slamova R, Trckova M, Zraly Z, Pavlik I. Alternatives to antibiotic growth promoters in prevention of diarrhoea in weaned piglets: a review. Vet Med. 2010;55:199-224.

133. Krumbeck JA, Maldonado-Gomez MX, Martinez I, Frese SA, Burkey TE, Rasineni K, et al. In vivo selection to identify bacterial strains with enhanced ecological performance in synbiotic applications. Appl Environ Microbiol. 2015:81:2455-65.

134. Krause DO, Bhandari SK, House JD, Nyachoti CM. Response of nursery pigs to a synbiotic preparation of starch and an anti-Escherichia coli K88 probiotic. Appl Environ Microbiol. 2010;76:8192-200.

135. Guerra-Ordaz AA, Gonzalez-Ortiz G, La Ragione RM, Woodward MJ, Collins JW, Perez JF, et al. Lactulose and Lactobacillus plantarum, a potential complementary synbiotic to control postweaning colibacillosis in piglets. Appl Environ Microbiol. 2014;80:4879-86.

136. Lee C. Porcine epidemic diarrhea virus: an emerging and re-emerging epizootic swine virus. Virol J. 2015:12:1-16.

137. Zhang Y, Zheng P, Yu B, He J, Yu J, Mao XB, et al. Dietary spray-dried chicken plasma improves intestinal barrier function and modulates immune status in weaning piglets. J Anim Sci. 2016;94:173-84.

138. Gerber PF, Xiao CT, Chen Q, Zhang J, Halbur PG, Opriessnig T. The spraydrying process is sufficient to inactivate infectious porcine epidemic diarrhea virus in plasma. Vet Microbiol. 2014;174:86-92.

139. Xiao H, Shao F, Wu M, Ren W, Xiong X, Tan B, et al. The application of antimicrobial peptides as growth and health promoters for swine. J Anim Sci Biotechnol. 2015;6:1-6.

140. Zong X, Hu W, Song D, Li Z, Du H, Lu Z, et al. Porcine lactoferrin-derived peptide LFP-20 protects intestinal barrier by maintaining tight junction complex and modulating inflammatory response. Biochem Pharmacol. 2016;104:74-82.

141. Cutler SA, Lonergan SM, Cornick N, Johnson AK, Stahl CH. Dietary Inclusion of colicin E1 is effective in preventing postweaning diarrhea caused by F18-positive Escherichia coli in pigs. Antimicrob Agents Chemother. 2007:51:3830-5.

142. Guilhelmelli F, Vilela N, Albuquerque P, Derengowski Lda S, Silva-Pereira I, Kyaw CM. Antibiotic development challenges: the various mechanisms of action of antimicrobial peptides and of bacterial resistance. Front Microbiol. 2013;4:353.

143. Chernysheva LV, Friendship RM, Gyles CL, Dewey CE. Field trial assessment of the efficacy of specific egg-yolk antibody product for control of postweaning E. coli diarrhea. Vet Ther. 2003:4:279-84.

144. Zhang J, Li Z, Cao Z, Wang L, Li X, Li S, et al. Bacteriophages as antimicrobial agents against major pathogens in swine: a review. J Anim Sci Biotechnol. 2015;6:39

145. Lee CY, Kim SJ, Park BC, Han JH. Effects of dietary supplementation of bacteriophages against enterotoxigenic Escherichia coli (ETEC) K88 on clinical symptoms of post-weaning pigs challenged with the ETEC pathogen. J Anim Physiol Anim Nutr (Berl). 2016. doi:10.1111/jpn.12513.

146. Levin BR, Bull JJ. Population and evolutionary dynamics of phage therapy. Nat Rev Microbiol. 2004:2:166-73.
147. Tactacan GB, Cho SY, Cho JH, Kim IH. Performance responses, nutrient digestibility, blood characteristics, and measures of gastrointestinal health in weanling pigs fed protease enzyme. Asian Australas J Anim Sci. 2016;29:998-1003.

148. De Greeff A, Resink JW, Van Hees HM, Ruuls L, Klaassen GJ, Rouwers SM et al. Supplementation of piglets with nutrient-dense complex milk replacer improves intestinal development and microbial fermentation. J Anim Sci. 2016;94:1012-9.

149. Subramaniam MD, Kim IH. Clays as dietary supplements for swine: a review. J Anim Sci Biotechnol. 2015;6:1-9.

150. Ayrle H, Mevissen M, Kaske M, Nathues H, Gruetzner N, Melzig M, et al. Medicinal plants - prophylactic and therapeutic options for gastrointestinal and respiratory diseases in calves and piglets? A systematic review. BMC Vet Res. 2016;12:1.

151. Sbardella M, Perina D, Andrade C, Santos C, Cairo P, Marques E, et al. Effects of dietary hop $\beta$-acids or colistin on the performance, nutrient digestibility, and intestinal health of weanling pigs. Anim Feed Sci Technol. 2016;217:67-75.

152. Ye G, Qiu Y, He X, Zhao L, Shi F, Lv C, et al. Effect of two macrocephala flavored powder supplementation on intestinal morphology and intestinal microbiota in weaning pigs. Int J Clin Exp Med. 2015;8:1504.

153. Årdal C, Outterson K, Hoffman SJ, Ghafur A, Sharland M, Ranganathan $\mathrm{N}$, et al. International cooperation to improve access to and sustain effectiveness of antimicrobials. Lancet. 2016;387:296-307.

154. Torrallardona D, Conde MR, Badiola I, Polo J, Brufau J. Effect of fishmeal replacement with spray-dried animal plasma and colistin on intestinal structure, intestinal microbiology, and performance of weanling pigs challenged with Escherichia coli K99. J Anim Sci. 2003;81:1220-6.

155. Yin $F$, Liu $Y$, Yin $Y$, Kong $X$, Huang $R$, Li $T$, et al. Dietary supplementation with Astragalus polysaccharide enhances ileal digestibilities and serum concentrations of amino acids in early weaned piglets. Amino Acids. 2009;37:263-70

156. Tang Z, Yin Y, Zhang Y, Huang R, Sun Z, Li T, et al. Effects of dietary supplementation with an expressed fusion peptide bovine lactoferricin-lactoferrampin on performance, immune function and intestinal mucosal morphology in piglets weaned at age $21 \mathrm{~d}$. Br J Nutr. 2009:101:998.

157. Furbeyre H, van Milgen J, Mener T, Gloaguen M, Labussiere E. Effects of dietary supplementation with freshwater microalgae on growth performance, nutrient digestibility and gut health in weaned piglets. Animal. 2017;11:183-92

158. Trevisi P, Latorre R, Priori D, Luise D, Archetti I, Mazzoni M, et al. Effect of feed supplementation withlive yeast on the intestinal transcriptome profile of weaning pigs orally challenged with Escherichia coli F4. Animal. 2017;11:33-4

159. Kirby GM. Systems biology in livestock health and disease. In: Te Pas M, Woelders H, Bannink A, editors. Systems biology and livestock science. Hoboken: Wiley; 2011. p. 83-108.

\section{Submit your next manuscript to BioMed Central and we will help you at every step:}

- We accept pre-submission inquiries

- Our selector tool helps you to find the most relevant journal

- We provide round the clock customer support

- Convenient online submission

- Thorough peer review

- Inclusion in PubMed and all major indexing services

- Maximum visibility for your research

Submit your manuscript at www.biomedcentral com/submit 